\title{
DEMOCRACIA PARITARIA E IMPACTO DE GÉNERO EN LAS POLÍTICAS PÚBLICAS: ANÁLISIS DEL CASO DE LA COMUNIDAD AUTÓNOMA VASCA
}

JUANA GOIZUETA VÉRTIZ 


\section{SUMARIO:}

I. INTRODUCCIÓN. II. LA DEMOCRACIA REPRESENTATIVA COMO PUNTO DE ARRANQUE. III. DE LA DEMOCRACIA REPRESENTATIVA A LA DEMOCRACIA PARITARIA: EL SISTEMA DE CUOTAS. IV. LA PERSPECTIVA DE GÉNERO EN LAS POLÍTICAS AUTONÓMICAS: EL CASO DE LA CAPV. 4.1. Presencia de mujeres en el Parlamento y en el Gobierno Vasco. 4.2. La evaluación del impacto de género en las políticas públicas autonómicas. 4.3. Las iniciativas parlamentarias y gubernamentales en materia de igualdad V. ALGUNAS REFLEXIONES CONCLUSIVAS. 


\title{
DEMOCRACIA PARITARIA E IMPACTO DE GÉNERO EN LAS POLÍTICAS PÚBLICAS: ANÁLISIS DEL CASO DE LA COMUNIDAD AUTÓNOMA VASCA
}

\author{
JUANA GOIZUETA VÉRTIZ1 \\ Profesora Agregada de Derecho Constitucional \\ $\mathrm{UPV} / \mathrm{EHU}$
}

\section{INTRODUCCIÓN}

El Pacto que da origen a la creación del Estado parte de un concepto de ciudadanía del que resultan excluidas las mujeres. Una realidad que ha sido descrita de forma muy acertada por P. Lucas Verdú para quien «la normación e institucionalización de los aparatos estatales concebidos por la imaginación jurídico política burguesa se hizo sin considerar prácticamente a la otra mitad del género humano» ${ }^{2}$. Esa exclusión de las mujeres, y su no consideración como sujeto político social, hace que la democracia representativa nazca viciada en tanto deficitaria desde la óptica de la igualdad.

Una situación que no tiene encaje en el modelo de Estado social y democrático de Derecho que propugna la Constitución de 1978. Una Constitución que reconoce la igualdad en sus diversas manifestaciones entre las que cabe destacar la que debe predicarse del derecho de participación política directamente o a través de representantes o del derecho al acceso a cargos públicos. Aunque lo cierto es que este deber de observancia de la igualdad en la selección y elección de nuestros representantes ha tenido que sortear no pocos obstáculos.

1 Facultad de Derecho, UPV/EHU, Po Manuel de Lardizábal, 2, 20018, Donostia-San Sebastián. Email: juana.goizueta@ehu.eus.

Este trabajo se enmarca dentro del Grupo de Investigación del Gobierno Vasco sobre «Derechos Fundamentales y Unión Europea. Especial referencia al ELSJ en la UE» (IT-1190-19).

2 LUCAS VERDÚ, P. (1981-1982), «El valor constitucional de la igualdad y la condición femenina», Revista de Política Comparada, $\mathrm{n}^{\circ} 7$. 
Partiendo de estas premisas, este trabajo analiza la participación política de las mujeres y su vinculación con el diseño y ejecución de políticas públicas con perspectiva de género en el caso del País Vasco. Lo que se plantea es si la mayor presencia de mujeres en órganos de toma de decisión política en el País Vasco que favorece la democracia paritaria ha permitido a estas ejercer un papel transformador de la sociedad que conduzca a una sociedad más igualitaria. Para este análisis se ha empleado una metodología de investigación jurídica, complementada con información disponible sobre evaluaciones de impacto de género de las políticas públicas vascas.

\section{LA DEMOCRACIA REPRESENTATIVA COMO PUNTO DE ARRANQUE}

El concepto de democracia constituye como sostiene M. Barrère un «típico» concepto contestado» ${ }^{3}$. A ello debe añadirse que no existe una única modalidad de democracia. Así, junto a la democracia representativa, -que constituye objeto de análisis en este apartado-, puede distinguirse, siguiendo a J. Baños, entre la participativa -que viene a potenciar los valores de responsabilidad, igualdad y autonomía-, la deliberativa - calificada de mejor propuesta democrática en tanto que asegura la paridad $^{4}$ - y la denominada radical ${ }^{5}$. Por su parte, para $R$. Mestre la distinción debe hacerse entre democracia participativa -en la que considera incluida la deliberativa- y radical $^{6}$. La autora considera que la democracia participativa aumentaría la igualdad de los ciudadanos a través de la participación y deliberación ciudadanas ${ }^{7}$. En cambio, J. Cohen y A. Fung aluden a la democracia radical aglutinando en ella la participativa y la deliberativa ${ }^{8}$, y a todo ello cabe añadir la democracia genérica ${ }^{9}$ o la democracia paritaria solo por mencionar algunos de los modelos.

Ello, no obstante, conviene aclarar 2 cuestiones:

3 BARRÈRE, M (2013), «Versiones de la democracia, feminismos y política radical», en MESTRE I MESTRE, R.M. y ZUÑIGA-AÑAZCO, J. (Coords.), Democracia y participación política de las mujeres. Visiones desde Europa y América Latina, Valencia Tirant lo Blanch, p. 46.

4 FRASER, N. (2006) «Una deformación que hace imposible el reconocimiento: Réplica a Axel Honneth», en FRASER, N. y HONNETH A., Redistribución o reconocimiento. Un debate político-filosófico, Coruña y Madrid, Ediciones Morata.

5 BAÑOS, J. (2006) Teorías de la democracia: debates actuales, Andamios, Vol. 2, núm. 4, pp. 46 y ss.

6 MESTRE, R. M. (2013) «Ciudadanía, autonomía y participación política de las mujeres en democracia», en MESTRE I MESTRE, R.M. y ZUÑIGA-AÑAZCO, J. (Coords.), Democracia y participación politica de las mujeres. Visiones desde Europa y América Latina, Valencia, Tirant lo Blanch, p. 16.

MESTRE, R. M. (2013) «Ciudadanía, autonomía y participación política ...», ob. cit., p. 16.

8 COHEN J. y FUNG, A (2004) «Radical democracy», Swiss Journal of political science, Vol. 10, núm. 4, pp. 23-34.

9 LAGARDE, M. (2005) Para mis socias de la vida, Madrid, Horas y Horas, pp. 169 y ss. 
- Primero, no es objetivo de este trabajo examinar en profundidad los diferentes tipos de democracia o elaborar un excursus sobre sus diferentes modelos, algo que ya ha sido ampliamente estudiado. Y tampoco lo es el estudiar sus fortalezas y debilidades con la intensidad que exigiría la deconstrucción del concepto. En fin, nuestro objetivo consiste en llamar la atención sobre las debilidades de la democracia representativa para otorgar a las mujeres la capacidad que les corresponde como sujetos políticos y examinar si la democracia paritaria y el sistema de cuotas han permitido lograr una adecuada representación ${ }^{10}$ de las mujeres que potencie el valor de la igualdad y todo ello circunscrito al ámbito autonómico vasco.

- Segundo, cuando hablamos de participación política en este trabajo nos referimos a una de las modalidades previstas como tal en el modelo de democracia liberal, en concreto, aquella que se articula en el seno de las instituciones reconocidas por el Estado en los diferentes niveles de poder, lo que no significa obviamente negar otras formas de la participación política lo que sería, a todas luces, acoger una acepción demasiado reduccionista de lo que es la política y negar la diferencia entre la política y lo político ${ }^{11}$. Esto es, la participación política es tanto la que se articula a través del ejercicio del derecho de sufragio o la que se vehicula a través de espacios de decisión «informa-

10 Sobre la teoría de la representación son de obligada lectura la siguiente literatura clásica: HOBBES, T (1994), El Leviatán, Barcelona, Altaya, 1994; LOCKE, J. (1994), Segundo Tratado sobre el gobierno civil, Barcelona, Altaya; o PITKIN, H. F. (2014), El concepto de representación, Madrid, Centro de Estudios Políticos y Constitucionales. Y también son materiales de interés, entre otros: TORRES DEL MORAL, A. (1975),, «Democracia y representación en los orígenes del Estado Constitucional», Revista de Estudios Políticos, núm. 203, pp. 145-212; PORTERO MOLINA, J. A. (1991), «Sobre la representación política», Revista del Centro de Estudios Constitucionales, núm. 10, septiembre-diciembre, pp.89-119; PALOMAR MALDONADO, E. M. (1997), «Sobre la representación en la teorización del racionalismo (Siglos XVII y XVIII), Revista de la Facultad de Derecho de la Universidad Complutense, núm. 87, pp. 225258; DUSO, G (2004), «Génesis y lógica de la representación política moderna», Fundamentos: Cuadernos monográficos de teoría del Estado, Derecho público e Historia constitucional, núm. 3, pp.1-38 ; BLANCO VALDÉS, R. L. (2010), La construcción de la libertad, Madrid, Alianza; y FERNÁNDEZ CAÑUETO, D. (2019), Representación política y Constitución española, Madrid, Marcial Pons.

11 BARRÈRE, M. explica de forma muy precisa, y aludiendo a la opinión de YOUNG, las distintas formas de cómo ha de entenderse la participación política. Afirma que: «(...) no es necesario participar en las instituciones estatales o en las organizaciones reconocidas por el Estado para participar políticamente. Engrosar manifestaciones, movimientos y asociaciones, potenciar foros y espacios de discusión en distintos espacios (también académicos), por no hablar del activismo en la red, es también participación política, aunque esto implique poner en cuestión la manera en la que se entiende por tal en el modelo de democracia liberal, demasiado acostumbrada a reducir la participación política a las posibilidades de votar y afiliarse a partidos, así como a la práctica por estos del juego de las mayorías parlamentarias» (BARRÈRE, M. (2013), «Versiones de la democracia, feminismos ...», ob. cit., p. 11). En la misma línea, MARTÍNEZ, E. y ELIZONDO, A. (2006) «Participación política de las mujeres: presencias y ausencias en la Política Vasca», Vasconia, Vol. 35, p. 492.

(C) UNED. Revista de Derecho Politico

N. ${ }^{\circ} 109$, septiembre-diciembre 2020, págs. 153-189 
les» ${ }^{12}$, léase al margen de la participación en el gobierno o parlamento ${ }^{13}$. Así, la participación política en el escenario de la Comunidad Autónoma Vasca la entenderemos referida a la participación en los centros de toma de decisión política: en el parlamento y ejecutivo autonómico. En suma, a la denominada participación política formal.

Hechas estas previas consideraciones, debe señalarse que la democracia representativa puede entenderse, siguiendo a Sieyès, como la forma que adopta la voluntad nacional para hacerse entender o, como afirmara Constant, como la forma que permite evadirse de la carga de participar directamente en la decisión de los asuntos públicos. La cuestión relevante es saber quiénes conforman la voluntad nacional o quienes se consideran representantes capaces de expresarse en nombre del pueblo ${ }^{14}$. En fin, ¿qué ciudadanía tiene cabida en la democracia representativa? Esta es la pregunta que conviene plantearse. $\mathrm{Y}$ es que a los efectos que ahora interesa es preciso llamar la atención sobre el hecho de que la inicial construcción de la idea de la representación que subyace en la democracia representativa obvia la igualdad entre mujeres y hombres.

Como es conocido se ha negado a las mujeres, en general, su condición de sujetos de derechos y, en particular, la de sujetos políticos con posibilidad de ejercer el derecho de sufragio. La mencionada exclusión de las mujeres de la democracia radica en las teorías contractualistas modernas de Hobbes, Locke y Rousseau que no consideran a estas como parte del contrato originario relegándolas a la esfera privada y excluyéndolas del derecho de voto hasta bien avanzado el S. XX reafirmándose así la estructura patriarcal de la sociedad ${ }^{15}$, por lo que es necesaria la reactualización del contrato social para lograr una verdadera capacidad inclusiva de la democracia.

La participación para ser verdaderamente representativa, -esto es, para que no haya grupos excluidos-, ha de asegurar como conditio sine qua non el acceso equitativo o equilibrado de todos los grupos sociales y por lo que a nosotros nos interesa del

12 Sobre este particular, R. MESTRE apunta al feminismo institucional como causa del debilitamiento de la participación política informal de las mujeres (MESTRE, R. M (2013) «Ciudadanía, autonomía y participación política ...», ob. cit., p. 19).

13 En este sentido, J. MARTÍNEZ PALACIOS distingue entre experiencias por invitación en las que la administración pone a disposición de la ciudadanía y le invita a participar en la esfera pública y experiencias por irrupción en las que la iniciativa nace de la propia ciudadanía — por ejemplo, el movimiento $15 \mathrm{M}$ o la primavera árabe en países de África y Oriente Próximo (J. MARTÍNEZ PALACIOS, J. (2015) «¿Le importa el sexo a la democracia participativa?», Revista de Estudios Políticos, núm. 168, abril-junio, p. 154)

14 Para ROUSSEAU, J. J. (1990), la idea misma de representación conlleva la anulación del pueblo (El contrato social, Madrid, Alianza Editorial). En cambio, M. A. PRESNO LINERA sostiene con acierto, que la complejidad de las sociedades hace aconsejable la participación por medio de representantes «sin que ello implique una anulación de la voluntad de los destinatarios de las decisiones tomadas por los representantes» (PRESNO LINERA, M. A. (2000), Los Partidos Políticos en el Sistema Constitucional Español, Cizur, Thomson Reuters Aranzadi, p. 41).

15 COBO BEDIA, R. (2004), Sexo, Democracia y Poder político, Feminismo/s, Vol. 3, junio, pp. $17-24$. 
grupo de las mujeres a los centros o espacios de decisión política, a lo que cabe añadir además la necesidad de lograr la sintonía entre los conceptos de representación y representatividad. Lo que ocurre es que la democracia representativa no asegura siempre el necesario equilibrio entre el binomio representación-representatividad. Se trataría de lograr lo que se ha venido a denominar «democracia distributiva» ${ }^{16}$. En esta línea emerge la democracia paritaria como herramienta capaz de garantizar un mayor nivel de representatividad femenina.

En fin, la democracia representativa es el punto de arranque en el sentido de que resulta necesario un proceso de transformación que permita a través de la utilización del sistema de cuotas transitar hacia una democracia paritaria a la que le prestaremos atención en el siguiente apartado.

\section{DE LA DEMOCRACIA REPRESENTATIVA A LA DEMOCRACIA PARITARIA: EL SISTEMA DE CUOTAS}

La historia demuestra que la democracia representativa no garantiza la representatividad $^{17}$ de la sociedad en su globalidad, por ello resulta necesario adoptar medidas que permitan el tránsito hacia la democracia paritaria. La democracia aun siendo representativa no asegura la representatividad de las mujeres en la escena política, afirmación que se sustenta sobre la base de que este modelo de democracia constituye un cauce para reproducir el poder masculino reflejo de una sociedad patriarcal y en este sentido se sostiene que la relación entre democracia y representatividad lo es de fricción. De modo que, si queremos incidir en la verdadera calidad democrática del sistema, la democracia debe ser representativa y paritaria. Una democracia paritaria que, como han defendido B. Rodríguez Ruíz y R. Rubio Marín, no solo resulta «compatible con los compromisos asumidos por el Estado, como forma de organización política moderna, para con la representación general y unitaria» sino que además viene a «completar el tránsito del Estado liberal al Estado democrático iniciado con el sufragio universal» defendiendo incluso la imposición por ley de la paridad ${ }^{18}$.

La democracia paritaria exige la reformulación del concepto de la representación y la igualdad acorde con las exigencias de la democracia y con la protección de los derechos fundamentales. En este sentido, J. Martínez Palacios apuesta por la necesaria reactualización del contrato social para normalizar la participación ciudadana- la de

16 BOAVENTURA DE SOUSA, S. (2004), Democratizar la democracia. Los caminos de la democracia participativa, México, Fondo de cultura económica, p. 48

17 La representatividad alude al grado de similitud de los representados y los representantes, y la representación al proceso para elegir a los representantes.

18 RODRIGUEZ RUÍZ, B. y RUBIO MARÍN, R. (2007), «De la paridad, la igualdad y la representación en el Estado Democrático», Revista Española de Derecho Constitucional, n ${ }^{\circ}$ 1, septiembrediciembre, p. 118.

(C) UNED. Revista de Derecho Político

N. ${ }^{\circ} 109$, septiembre-diciembre 2020, págs. 153-189 
toda la ciudadanía- como herramienta para ensanchar la democracia representativa ${ }^{19}$.

El concepto de democracia paritaria ${ }^{20}$, -en tanto instrumento de perfeccionamiento del sistema democrático-, se recoge por vez primera en instrumentos carentes de valor normativo en la última década del S. xx. Aluden a ella el Informe del Consejo de Europa de 1989 titulado «Democracia paritaria. 40 años de actividad del Consejo de Europa» y la Declaración de Atenas de 1992, que contempla la paridad en su sentido finalista. Esto es, como cauce que solo persigue la mera presencia paritaria obviando su potencialidad para combatir la discriminación que sufren las mujeres.

La Declaración de Atenas alude genéricamente a la necesidad de adoptar medidas para asegurar la democracia paritaria, sin más especificación. Aunque no podemos obviar que ya en la década de los 70 el sistema de cuotas- en tanto principio articulador de la democracia paritaria- se sitúa en la agenda internacional tras reconocerse expresamente en la Convención sobre la eliminación de toda forma de discriminación contra la mujer aprobada por Naciones Unidas en 1979.

Llegados a este punto, es necesario definir la democracia paritaria. Para A. Sierra González tal fórmula: «(...) no pretende solo una nueva correlación de géneros en los órganos de representación político-institucional, sino también una vertebración social a través de la cual se universalice un cuadro de responsabilidades compartidas tanto en el ámbito público como en el privado-doméstico, expresivo de una nueva ciudadanía plenamente incorporada a los procesos de formulación, decisión, ejecución y control de las políticas públicas. En este contexto, las mujeres aparecen como un genérico emancipador y como un actor político con capacidad de intervención y de negociación política en sociedades patriarcales» ${ }^{21}$.

Así pues, la incorporación de la paridad ${ }^{22}$ en la democracia representativa (democracia paritaria) persigue el logro de una sociedad más justa, equilibrada e igualitaria,

19 MARTÍNEZ PALACIOS, J. (2015), «¿Le importa el sexo a la democracia participativa?», ob. cit., pp. 152.

20 Sobre la democracia paritaria, entre otros: COBO, R. (2002), «Democracia paritaria y sujeto político feminista», Anales de la Cátedra Francisco Suárez, Vol. 36, pp. 29-44; GONZÁLEZ, A. S. y DE LA NUEZ, Ma del P. (Eds.) (2007), Democracia paritaria, Barcelona, Laertes; MACÍAS, M. (2008), La democracia representativa paritaria, Córdoba, Universidad de Córdoba; SEVILLA, J. (2004), Mujeres y ciudadanía: la democracia paritaria, Valencia, Universidad de Valencia.

${ }^{21}$ SIERRA, A. (2007) «La democracia paritaria y las paradojas ocultas de la democracia representativa», en GONZÁLEZ, A. S. y NUEZ RUÍZ, Ma del P. (Eds.) Democracia paritaria, ob. cit., p. 194.

22 Sobre la paridad pueden consultarse, por ejemplo: MARINETTE, S. (2004), Parité. Le Conseil de l'Europe et la participation des femmes à la vie politique, Conseil de l'Europe, Estrasburgo; LEPINARD, E. (2007), L'égalité introuvable: La parité, les féministes et la République, Presses de la Fondation nationale des sciences politiques, París; MERTENS DE WILMARS, F. (2015), «La paridad a la luz de la equidad. Una nueva lectura del principio de igualdad. Experiencias constitucionales en Bélgica, Francia y España», Revista Europea de Derechos Fundamentales, no 26, pp. 169-192.; VERDIER, M-F. (2011), «Egalité-parité, universalisme-différentialisme. Le droit de suffrage en France et le genre», Politeia, $\mathrm{n}^{\circ}$ 19; RUÍZ RODRÍGUEZ, B. y RUBIO MARÍN, R. (2007), «De la paridad, la igualdad y la representación en el Estado democrático», REDC, no 81, pp. 115-159; RUIZ-RICO RUIZ, G. (2009), 
puesto que la presencia de las mujeres en el sistema democrático, por muy importante que sea, no es aval suficiente de su representatividad. Ahora bien, la paridad, no es una finalidad en sí misma, no es el punto de llegada y ha de servir para que la presencia de las mujeres en los órganos de toma de decisiones garantice la inclusión de la diferencia en el sentido de reequilibrar las diferencias grupales y esto ocurrirá cuando se tome verdadera conciencia de la situación de subordiscriminación que estas padecen: cuando se reconozca que las existencias de los sistemas de poder producen subordiscriminación intergrupal. De lo contrario, es decir, si la paridad la entendemos solo en clave de mera presencia de mujeres en cargos institucionales solo estaremos materializando políticas de igualdad formal situándonos en lo que N. Fraser denomina «representación fallida» que se produce cuando el funcionamiento de las reglas del juego político produce la exclusión de alguien que en principio está incluido en el conjunto de personas que han de participar en situación de paridad en tal juego ${ }^{23}$.

En fin, la paridad será eficaz si ello sirve para que las políticas públicas sean diseñadas desde una perspectiva de género ${ }^{24}$ que preserve los intereses de las mujeres en el terreno de la adopción de las decisiones políticas. Las políticas públicas no escapan de las garras del sistema sexo-género siendo un espejo en donde se refleja, en muchos casos, una sociedad eminentemente patriarcal que coadyuva a la preservación de los roles tradicionales de género. Por ello, es necesario que las mujeres alcancen, a través de la paridad, cuotas efectivas de poder político que les permita desplegar su potencial transformador. La paridad, entendida como presencia numérica, reivindica el $50 \%$ de presencia de las mujeres en las listas electorales, pero la misma puede superarse mediante la incorporación al sistema democrático del sistema de cuotas.

Centrándonos ahora en el denominado sistema de cuotas, cabe señalar que hay que esperar hasta la década de los 90 para que las legislaciones nacionales las incorporen, abriendo así la posibilidad de aumentar la presencia de las mujeres más allá del $50 \%$ que sería el techo que marca la paridad. Interesa llamar la atención sobre el hecho de que las cuotas conectan no solo con el bajo porcentaje de mujeres presentes en la política sino con la discriminación que sufren estas en la sociedad.

En este orden de cosas, en Europa es Italia quien inicia esta andadura aprobando en 1993 una ley de cuotas que será declarada inconstitucional 2 años más tarde, pos-

\footnotetext{
«Paridad y acción positiva en el Derecho electoral autonómico», en El Derecho electoral de las Comunidades Autónomas, revisión y mejora, Gálvez Muñoz, L. A. (Coord.), Centro de Estudios Políticos y Constitucionales, Madrid, pp. 145-184; SALAZAR BENÍTEZ, O. (2018), «Paridad y justicia de género. Algunas reflexiones críticas sobre las políticas de igualdad en España», Comunicación y Género, 2018, pp. 5-24.

23 FRASER, N. (2006) «Una deformación que hace imposible el reconocimiento: Réplica a Axel Honneth», en FRASER, N. y HONNETH A., Redistribución o reconocimiento. Un debate político-filosófico, Coruña y Madrid, Ediciones Morata, pp. 149-175.

24 Para un sector doctrinal, perspectiva de género significa que las mujeres, y en particular, las corrientes feministas, aportan una nueva forma de ver el mundo diferente a la visión androcentrista persiguiendo el cuestionamiento, políticas y eco del orden patriarcal y de las instituciones jurídicas y económicas derivadas del mismo. A título de ejemplo, PATEMAN, C. (1995), El Contrato sexual, Barcelona, Anthropos.
}

(C) UNED. Revista de Derecho Politico 161

N. ${ }^{\circ} 109$, septiembre-diciembre 2020, págs. 153-189 
teriormente Bélgica hace lo propio en 1994, Francia reforma en 1999 su Constitución a estos efectos ${ }^{25} \mathrm{y}$, por lo que respecta en particular al caso español, España acoge primero el sistema de cuotas de partido en la década de los 70 para posteriormente aprobar en 2007 la Ley Orgánica para la Igualdad efectiva de Mujeres y Hombres mediante la cual se incorpora el principio de composición equilibrada de mujeres y hombres en candidaturas electorales, en los puestos de la Administración Pública y en los órganos de decisión de las empresas privadas, asumiendo las cuotas legislati$\operatorname{vas}^{26}$. De este modo, y como apunta T. Verge Mestre, con la entrada en vigor de la Ley de Igualdad nuestro país se convierte en uno de los cinco países «cuya cuota se compromete con la democracia paritaria, es decir, con una representación equilibrada de mujeres y hombres, traducida en un porcentaje de representación mínima para cualquiera de los dos sexos del $40 \% »^{27}$.

Conviene recordar que el Comité de vigilancia de la CEDAW ya recomienda al Estado español en un informe de julio de 2004 «que considere la posibilidad de modificar la Ley Orgánica del Régimen Electoral General, a fin de lograr un equilibrio de la cantidad de hombres y mujeres que ocupan cargos políticos». Así, la Ley Orgánica 3/2007 para la Igualdad efectiva de Mujeres y Hombres modifica la Ley Electoral General incorporando el principio de presencia equilibrada en las candida-

25 Téngase en cuenta que la Decisión del Consejo constitucional francés no $82-148$, de 18 de noviembre de 1982, declara inconstitucional la disposición según la cual en las listas de las candidaturas de representación municipal no podían figurar más de un $75 \%$ de personas del mismo sexo, y esto en base al art. 3 de la Constitución y al art. 6 de la Declaración de los Derechos del hombre y del ciudadano. En concreto, el Consejo Constitucional francés sostiene que: «la calidad de ciudadano abre el derecho de voto y la elegibilidad en condiciones idénticas a todos quienes no son excluidos por razón de edad, incapacidad o nacionalidad, o por una razón que tienda a preservar la libertad del elector o la independencia del elegido, que esos principios de valor constitucional se oponen a toda división por categorías de los electores o de los elegibles y que eso es así para todo sufragio político», de modo que a mi entender se parte de un concepto de igualdad que puede identificarse con la indiferenciación olvidándose de la existencia de desigualdades grupales.

Aunque lo cierto es que la Ley de 6 de junio de 2000, conocida como ley de la paridad, obligaba a los partidos políticos a presentar un número igual de mujeres y hombres en las elecciones regionales, municipales, senatoriales y europeas. Así en el caso de Francia la paridad legalmente impuesta sirvió para superar el \% de plazas reservadas para las mujeres por el sistema de cuotas — cifrado en un $25 \%$ llegando a una reserva del $50 \%$ para cada sexo. De modo que en Francia esto provoca el rechazo de las cuotas y la paridad surge entonces como alternativa a las cuotas, lo que conlleva que la fórmula paritarista francesa impide utilizar el sistema de cuotas para superar el techo del $50 \%$ que impone la paridad.

26 Sobre los efectos de la adopción del principio de composición equilibrada en la Ley de Igualdad de 2007, resulta interesante DELGADO SOTILLOS, I. (2011), Alcanzando el equilibrio. El acceso y la presencia de las mujeres en los parlamentos, Tirant Lo Blanch, Valencia. Asimismo, un estudio interesante sobre la Ley 3/2007 puede verse en: SALA FRANCO, T., BALLESTER PASTOR, Mª. A., BAÑO LEÓN, J. M, EMBID IRUJO, J. M y GOERLICH PESET, J. M. (2008), Comentarios a la Ley Orgánica 3/2007, de 22 de marzo, para la igualdad efectiva de mujeres y hombres. En concreto, la aportación de BALLESTER PASTOR, $\mathrm{M}^{\circ}$. A. titulado «Significado general y conceptual de la Ley Orgánica para la igualdad efectiva de mujeres y hombres» de las pp. 33 a la 111.

27 VERGE MESTRE, T. (2008), «Cuotas voluntarias y legales en España. La paridad a examen», Revista Española de Investigaciones Sociológicas, n 123, 2008, p. 125. 
turas electorales de modo que la proporción de hombres y mujeres en las listas ha de ser de 40/60. En concreto, el nuevo artículo 44bis de la LOREG, incorporado a través de la Disposición Adicional segunda de la Ley 3/2007, aplica el principio de presencia equilibrada a todo tipo de candidaturas políticas estableciendo que: «1. Las candidaturas que se presenten para las elecciones de diputados al Congreso, municipales y de miembros de los consejos insulares y de los cabildos insulares canarios en los términos previstos en esta Ley, diputados al Parlamento Europeo y miembros de las Asambleas Legislativas de las Comunidades Autónomas deberán tener una composición equilibrada de mujeres y hombres, de forma que en el conjunto de la lista los candidatos de cada uno de los sexos supongan como mínimo el cuarenta por ciento...». Por lo tanto, en las candidaturas de todo tipo de elecciones, salvo en el caso de las candidaturas de municipios de menos de 3000 habitantes, ningún sexo puede suponer menos del $40 \%$ del total de la lista de candidatos aplicándose ese equilibrio en tramos de 5 candidatos. Una modificación que fue tachada de inconstitucionalidad por el Partido Popular quien interpuso recurso de inconstitucionalidad ante el TC argumentando que tal medida vulneraba la libertad ideológica, el derecho de participación y limitaba el derecho de sufragio pasivo. Una duda de presunta inconstitucionalidad que fue disipada por el Alto Tribunal en su sentencia 12/2008 ${ }^{28}$ al considerar que la reforma de la LOREG encuentra cobertura en el mandato del artículo 9.2 de la Constitución. El Tribunal Constitucional afirmó que este precepto constitucional inviste de legitimidad a aquellas medidas legislativas tendentes a la consecución de la igualdad material considerando como tal la incluida en la LOREG. Una resolución que, si bien cabe aplaudir, es criticable porque en la argumentación solo se trae a colación el argumento numérico o proporcional eludiendo el problema de la discriminación y la falta de poder de las mujeres, poniendo el énfasis en la democracia paritaria numérica y obviando, lo verdaderamente clave, que es la democracia substantiva.

En todo caso, cabe afirmar para ir finalizando que el mencionado techo puede ser rebasado en el caso de las Asambleas legislativas autonómicas puesto que la misma Disposición Adicional Segunda de la Ley 3/2007 que modifica la LOREG contempla la posibilidad de que las leyes electorales de las Comunidades Autónomas puedan incorporar medidas que favorezcan una mayor presencia de mujeres en las candidaturas que se presenten ${ }^{29}$. Y así ocurre en la Comunidad Autónoma del País Vasco en la que se prevé al menos la presencia de un 50\% de mujeres. La Ley 4/2005, de 18 de febrero, para la Igualdad de Mujeres y Hombres, en su Disposición Final Cuarta,

28 Sobre la STC 12/2008, de 29 de enero, pueden consultarse, entre otros: BIGLINO, P., «Variaciones sobre las listas de composición equilibrada (Comentario a la STC 12/2008)», Revista Española de Derecho Constitucional, año 28, n 83, 2008, pp. 277-299; FIGUERUELO, A., «Representación política y democracia paritaria (a propósito de la sentencia del TC 12/2008, de 29 de enero), Revista Europea de Derechos Fundamentales, n 12, 2008, pp. 211-234; y, ÁLVAREZ RODRÍGUEZ, I., «Iguales, pero separados. Las cuotas electorales ante el Tribunal Constitucional (STC 12/2008, de 29 de enero)», Repertorio Aranzadi del Tribunal Constitucional, nº 7, 2008, pp. 13-40.

29 Art. 44. 2.bis) de la LOREG.

(C) UNED. Revista de Derecho Politico 163

N. ${ }^{\circ} 109$, septiembre-diciembre 2020, págs. 153-189 
incorpora a la Ley de Elecciones al Parlamento Vasco y a la Ley de Elecciones para las Juntas Generales de los 3 Territorios Históricos un nuevo párrafo con el que se fija la paridad absoluta en las listas electorales. En concreto, se prevé que: «Las candidaturas que presenten los partidos políticos, federaciones, coaliciones o agrupaciones de personas electoras estarán integradas por al menos un 50\% de mujeres».

Una previsión que fue recurrida ante el Tribunal Constitucional a través del recurso de inconstitucionalidad interpuesto por el Grupo Parlamentario del Partido Popular. Los recurrentes consideraron que la Ley 4/2005 suponía, en el aspecto recurrido, una invasión competencial, en concreto, de la competencia estatal contenida en el artículo 149.1.1 de la Constitución en relación al derecho de acceso a los cargos representativos del artículo 23.2 de la Norma Fundamental. Así pues, los recurrentes consideraron que el legislador autonómico había superado los límites que debía respetar al modificar la norma electoral mencionada. Aunque finalmente, la STC 13/2009, de 19 de enero ${ }^{30}$, que resolvió el recurso de inconstitucionalidad planteado entendió -con apoyo tanto en la LOREG como en el artículo 10.3 del propio Estatuto de Autonomía del País Vasco- que no se había superado los límites autonómicos. Así, el Tribunal Constitucional declara que la Ley vasca respeta el margen para establecer medidas igualadoras de discriminación positiva previsto en la LOREG lo que supone afirmar la constitucionalidad de los preceptos recurridos y por tanto desestimar el recurso interpuesto. A lo que añade el voto particular concurrente formulado por el magistrado Pérez Tremps que al ser medidas positivas han de responder a una lógica temporal de modo que tales medidas una vez cumplido su objetivo deberán ser reformuladas. Una declaración que como bien afirma I. Torres Muro, y conviene poner de relieve para ir finalizando, «no conlleva un cambio radical de nuestra concepción de la democracia» ${ }^{31}$ siendo necesario seguir debatiendo ante la necesidad de poner punto y final a la discriminación de las mujeres en las sociedades contemporáneas y, desde luego, también en la nuestra.

\section{LA PERSPECTIVA DE GÉNERO EN LAS POLÍTICAS AUTONÓMICAS: EL CASO DE LA CAPV ${ }^{32}$}

Llegados a este punto, y partiendo de la previsión contemplada en la Ley 4/2005, resulta necesario analizar si los avances que se han dado en el ámbito autonómico, -marco de referencia de nuestro estudio-, han quedado circunscritos al ámbito de la participación de las mujeres en términos de mera presencia en el órgano legislativo y ejecutivo autonómico o si el sistema de cuotas ha logrado tener una proyección de

30 Hay que constatar que el Tribunal Constitucional en esta ocasión se limitó prácticamente a reiterar los argumentos que ya había manejado en la ya mencionada Sentencia 12/2008, de 29 de enero.

31 TORRES MURO, I., «Las SSTC 12/2008, de 29 de enero, y 13/2009, de 19 de enero, sobre las cuotas electorales. Contenido, recepción y consecuencias», Aequalitas, n 24, 2009, p. 37.

32 Art. 4 de la Ley 4/2005. 
carácter sustantivo lo que significa hablar de impacto de género en las políticas públicas.

A los efectos mencionados, lógicamente, debemos analizar, cómo ha funcionado el sistema de cuotas para garantizar la participación política de las mujeres en el legislativo y ejecutivo autonómico ${ }^{33}$. Para ello, fijaremos nuestra mirada en cómo ha ido variando la presencia de mujeres en el Parlamento y Gobierno autonómico, pero también repararemos en la presencia de éstas en los cargos parlamentarios o gubernamentales (apartado 4.1). Ahora bien, conviene fijar el foco más allá del análisis cuantitativo y ello porque lo que realmente interesa es determinar si la presencia de mujeres garantiza la articulación de políticas públicas con impacto de género ${ }^{34}$. Para ello, resulta necesario manejar otros indicadores, aunque lo cierto es que, también estos adolecen de ciertas debilidades a los efectos que nos ocupan. En concreto, vamos a abordar el análisis de otros 2 indicadores: los informes de evaluación del impacto de género de las políticas públicas autonómicas (apartado 4.2) y las iniciativas parlamentarias y provenientes del Ejecutivo autonómico presentadas en la actual legislatura vinculadas con la igualdad (apartado 4.3). Veamos cada uno de estos aspectos.

Cómo se ha avanzado en la introducción para este trabajo se ha recurrido a una metodología clásica de investigación jurídica basada en fuentes de información legislativas, doctrinales y jurisprudenciales, complementada con indicadores objetivos de participación de las mujeres en las instituciones vascas, y con la información de los estudios de las políticas públicas vascas y los procesos de Evaluación previa del Impacto de Género (EIG) elaborados por el Instituto Vasco de la Mujer —Emakunde- ${ }^{35}$.

\subsection{Presencia de mujeres en el parlamento y en el gobierno vasco}

Se trata de visualizar la participación política de las mujeres en el Parlamento y en el Gobierno Vasco en aras a efectuar una lectura de la idoneidad o no del sistema

33 Para un análisis sobre las cuotas electorales legales a la hora de configurar candidaturas en el caso del País Vasco puede consultarse CAMPOS RUBIO, A. (2010), «La igualdad de mujeres y hombres: 30 años de Parlamento Vasco. La Ley 4/2005, de 18 de febrero, para la igualdad de hombres y mujeres», Corts Anuario de Derecho Parlamentario, n 23, pp. 19-45.

34 En este orden de cosas resulta muy interesante y también ilustrativa la opinión de DELGADO SOTILLOS, I. quien refiriéndose a los efectos de Ley de igualdad de 2007 afirma que «cuanto menos poder político hay en juego más fácil es encontrar mujeres cabeza de lista», de donde se deduce que la mayor presencia en términos cuantitativos de mujeres no se traduce en mayor poder de decisión de éstas ( Sistema Electoral y representación de las mujeres en el Parlamento. Análisis de los efectos de la Ley de Igualdad en la composición del Congreso de los Diputados tras las elecciones legislativas de 2008», Revista de Estudios Políticos, p. 160).

35 Emakunde, cumpliendo con las obligaciones legales para evaluar el impacto de género en las políticas públicas, ha realizado varios estudios para sistematizar y estandarizar las actuaciones legislativas, políticas, planes y presupuestos desde la perspectiva de género. Para estos estudios ha optado por utilizar diferentes técnicas de análisis de contenido, entrevistas y análisis cuantitativo del contenido de los expedientes de EIG (Emakunde, 2015, pp. 33; 133-158).

(C) UNED. Revista de Derecho Politico

N. ${ }^{\circ} 109$, septiembre-diciembre 2020, págs. 153-189 
de cuotas para logar la paridad en esos órganos decisorios. Si bien con carácter previo conviene evidenciar que resulta clave en este sentido la voluntad de los partidos políticos y ello porque son las listas cerradas y bloqueadas las que se utilizan, tal y como es conocido, para presentar las candidaturas en el caso de las elecciones autonómicas al Parlamento Vasco. Algo que ya pusieron de manifiesto J. Lovenduski y P. Norris al afirmar que «la relación entre el sistema electoral y la representación de las mujeres se encuentra mediada por los partidos, por su proceso de reclutamiento y selección de candidatos» ${ }^{36}$.

A pesar de que, en el ámbito estatal es la Ley del 2007 la que introduce el sistema de cuotas aludiendo a la necesidad de respetar el principio de composición equilibrada de mujeres y hombres en candidaturas electorales, en el ámbito autonómico vasco ya en el año 2005 a través de la Ley 4/2005, de 18 de febrero, para la Igualdad de Mujeres y Hombres se dan avances en este ámbito. Por un lado, en su Exposición de Motivos se declara como fin último de la ley la consecución de una sociedad igualitaria. Por otro lado, el art. 23 prevé que: «Todos los poderes públicos vascos deben promover que en el nombramiento y designación de personas para constituir o formar parte de sus órganos directivos y colegiados exista una presencia equilibrada de mujeres y hombres con capacitación, competencia y preparación adecuada. A tal fin, adoptarán las medidas normativas o de otra índole necesarias». Y, además, en su Disposición Final Cuarta se establece que: «las candidaturas que presenten los partidos políticos, federaciones, coaliciones o agrupaciones de personas electoras estarán integradas por al menos un 50 por ciento de mujeres. Se mantendrá esa proporción en el conjunto de la lista de candidatos y candidatas y en cada tramo de seis nombres. Las Juntas electorales del territorio histórico competentes solo admitirán aquellas candidaturas que cumplan lo señalado en este artículo tanto para las personas candidatas como para las suplentes»

Siguiendo tales mandatos, se incorpora a la Ley 5/1990 de 15 de junio de elecciones al Parlamento vasco, un nuevo párrafo 4 a su artículo 50, aludiendo a la necesidad de que en las listas electorales que presentan los partidos haya un $50 \%$ de mujeres. En suma, en este apartado analizando la presencia de mujeres en el Parlamento Vasco tendremos la ocasión de valorar la implementación de la Ley del año 2005 con relación a la exigencia de la presencia paritaria de mujeres en la Asamblea legislativa autonómica.

Y, asimismo, se modifica la Ley 7/1981, de 30 de junio de Gobierno estableciéndose que «en el Gobierno, ambos sexos estarán representados al menos en un $40 \%$ ». De modo que, podemos considerar que se produce un impacto positivo cuando se logra una representación equilibrada de mujeres y hombres, entendido como una presencia no inferior al $40 \%$.

Fijado cuál será el objeto de estudio en este apartado, centraremos el foco de atención en primer lugar en el Parlamento Vasco. Esta Asamblea legislativa se reúne

36 LOVENDUSKI, J. y NORRIS, P. (1993), Gender and Party Politics, Thousand Oaks, Sage. 
por primera vez el 26 de abril de 1980, de modo que lleva 40 años de andadura y han transcurrido ya 15 años desde que el legislador incorporarse la obligación de respetar la paridad en las listas electorales. Dicho resumidamente, se trata de analizar las consecuencias que en el seno de la Asamblea legislativa ha tenido la obligatoriedad de respetar la paridad se aplica desde la VIII legislatura. A estos efectos, afrontaremos el estudio desde una doble perspectiva: el análisis cuantitativo y cualitativo.

Situados en el plano del análisis meramente cuantitativo, es preciso observar los 2 siguientes indicadores: primero, la presencia de mujeres en el parlamento en cada una de las legislaturas; y segundo, la presencia de parlamentarias integrantes de los distintos Grupos Parlamentarios desde la legislatura anterior a la implantación del sistema de cuotas hasta la actualidad tanto en términos absolutos como porcentuales.

TABLA 1: número de parlamentarias por legislatura tanto en términos porcentuales como en términos absolutos ${ }^{37}$.

\begin{tabular}{|l|c|c|c|c|c|c|c|c|c|c|c|}
\hline $\begin{array}{c}\text { PRESENCIA } \\
\text { MUJERES } \\
\text { EN EL PV }\end{array}$ & $\begin{array}{c}1980- \\
1984\end{array}$ & $\begin{array}{c}\text { II } \\
1984-\end{array}$ & $\begin{array}{c}\text { III } \\
1986- \\
1990\end{array}$ & $\begin{array}{c}\text { IV } \\
1990- \\
1994\end{array}$ & $\begin{array}{c}\text { V } \\
1994- \\
1998\end{array}$ & $\begin{array}{c}\text { VI } \\
1998- \\
2001\end{array}$ & $\begin{array}{c}\text { VII } \\
2001- \\
2005\end{array}$ & $\begin{array}{c}\text { VIII } \\
2005- \\
2009\end{array}$ & $\begin{array}{c}\text { IX } \\
2009-\end{array}$ & $\begin{array}{c}\text { X } \\
2012- \\
2016\end{array}$ & $\begin{array}{c}\text { XI } \\
2016- \\
2020\end{array}$ \\
\hline $\begin{array}{l}\% \text { presencia } \\
\text { parlamentarias }\end{array}$ & $6,7 \%$ & $10,7 \%$ & $13,3 \%$ & $20 \%$ & $24 \%$ & $29,3 \%$ & $37,7 \%$ & $53,3 \%$ & $44 \%$ & $60 \%$ & $53,3 \%$ \\
\hline $\begin{array}{l}\text { Numero de } \\
\text { parlamentarias }\end{array}$ & 4 & 8 & 10 & 15 & 18 & 22 & 28 & 40 & 33 & 45 & 40 \\
\hline $\begin{array}{l}\% \text { presencia } \\
\text { parlamentarios }\end{array}$ & $93,3 \%$ & $89,3 \%$ & $86,7 \%$ & $80 \%$ & $76 \%$ & $70,7 \%$ & $62.7 \%$ & $46,6 \%$ & $56 \%$ & $40 \%$ & $46,6 \%$ \\
\hline $\begin{array}{l}\text { Número de } \\
\text { Parlamentarios }\end{array}$ & 56 & 67 & 65 & 60 & 57 & 53 & 47 & 35 & 42 & 30 & 35 \\
\hline
\end{tabular}

Si observamos la tabla 1 podemos hacer la siguiente lectura. Aunque resulta cierto que la presencia de las mujeres en el Parlamento Vasco ha ido creciendo paulatinamente desde las primeras elecciones de 1980, existe un destacadísimo aumento en la VIII legislatura pasándose de un $37,7 \%$ en la VII a un $53,3 \%$ con lo que por primera vez se logra una representación femenina mayoritaria en la Cámara. La razón de este aumento debemos situarlo, a nuestro parecer, en la previsión de la obligación legal de respetar la paridad en la composición de las listas a las elecciones al Parlamento Vasco. Así, parece que se ha cumplido con el objetivo de la modificación de la Ley 5/1990, de 15 de junio, de Elecciones al Parlamento Vasco que es, como se sabe, incrementar la presencia de mujeres en el Parlamento Vasco. Aun así, en la siguiente legislatura (IX) se aprecia un cierto descenso de presencia de parlamentarias (casi 10 puntos en términos porcentuales), una tónica que no vuelve a ocurrir ni en la $\mathrm{X}$ ni en

37 Fuente: elaboración propia a partir de datos extraídos de la Web del Parlamento Vasco.

(C) UNED. Revista de Derecho Político

N. ${ }^{\circ} 109$, septiembre-diciembre 2020, págs. 153-189 
la XI legislatura. En fin, el incremento de la presencia de mujeres en el Parlamento Vasco sigue creciendo -con la excepción de lo ocurrido en la IX legislatura- llegando en la X legislatura a alcanzar la cota más alta con un $60 \%$ de presencia femenina.

TABLA 2: Número de parlamentarias por grupo parlamentario desde la VII legislatura hasta la actualidad en términos absolutos y porcentuales ${ }^{38}$.

\begin{tabular}{|c|c|c|}
\hline $\begin{array}{c}\text { VII LEGISLATURA } \\
2001-2005\end{array}$ & MUJERES & HOMBRES \\
\hline EAJ/PNV & $8(33,3 \%)$ & $16(66,67 \%)$ \\
\hline PSE-EE/PSOE & $5(38,46 \%)$ & $8(61,54 \%)$ \\
\hline PP & $5(26,32 \%)$ & $14(73,68 \%)$ \\
\hline EH & $2(28,57)$ & $5(71,43 \%)$ \\
\hline EA & $3(37,5 \%)$ & $5(62,5 \%)$ \\
\hline EB-IU & $1(33,3 \%)$ & $2(66,67 \%)$ \\
\hline UA & $1(100 \%)$ & $0(0 \%)$ \\
\hline TOTAL & $25(33,4 \%)$ & $50(66,6 \%)$ \\
\hline
\end{tabular}

\begin{tabular}{|c|c|c|}
\hline $\begin{array}{c}\text { VIII LEGISLATURA } \\
\text { 2005-2009 }\end{array}$ & MUJERES & HOMBRES \\
\hline EAJ/PNV & $14(63,3 \%)$ & $8(36,4 \%)$ \\
\hline PSE-EE/PSOE & $10(55,5 \%)$ & $8(44,5 \%)$ \\
\hline PP & $6(40 \%)$ & $9(60 \%)$ \\
\hline EHAK & $8(88,9)$ & $1(11,1 \%)$ \\
\hline EA & $4(57,1 \%)$ & $3(42,9 \%)$ \\
\hline EB-IU & $0(0 \%)$ & $3(100 \%)$ \\
\hline ARALAR & $1(100 \%)$ & $0(0 \%)$ \\
\hline TOTAL & $43(57,3 \%)$ & $32(42,7 \%)$ \\
\hline
\end{tabular}

\begin{tabular}{|c|c|c|}
\hline $\begin{array}{c}\text { IX LEGISLATURA } \\
\text { 2009-2012 }\end{array}$ & MUJERES & HOMBRES \\
\hline EAJ/PNV & $17(56,6 \%)$ & $13(43,4 \%)$ \\
\hline PSE-EE/PSOE & $8(32 \%)$ & $17(68 \%)$ \\
\hline
\end{tabular}

38 Fuente: elaboración propia a partir de datos extraídos de la Web del Parlamento Vasco. 
DEMOCRACIA PARITARIA E IMPACTO DE GÉNERO EN LAS POLÍTICAS...

\begin{tabular}{|c|c|c|}
\hline $\begin{array}{c}\text { IX LEGISLATURA } \\
\text { 2009-2012 }\end{array}$ & MUJERES & HOMBRES \\
\hline PP & $5(38,46 \%)$ & $8(61,54 \%)$ \\
\hline EA & $0(0 \%)$ & $1(100 \%)$ \\
\hline EB-IU & $0(0 \%)$ & $1(100 \%)$ \\
\hline ARALAR & $2(50 \%)$ & $2(50 \%)$ \\
\hline UPYD & $0(0 \%)$ & $1(100 \%)$ \\
\hline TOTAL & $32(42,6 \%)$ & $43(57,4 \%)$ \\
\hline
\end{tabular}

\begin{tabular}{|c|c|c|}
\hline $\begin{array}{c}\text { X LEGISLATURA } \\
\text { 2012-2016 }\end{array}$ & MUJERES & HOMBRES \\
\hline EAJ/PNV & $14(51,9 \%)$ & $13(48,1 \%)$ \\
\hline EH-BILDU & $10(47,6 \%)$ & $11(52,4 \%)$ \\
\hline PSE-EE/PSOE & $8(50 \%)$ & $8(50 \%)$ \\
\hline PP & $4(40 \%)$ & $6(60 \%)$ \\
\hline UPD & 0 & $1(100 \%)$ \\
\hline TOTAL & $36(48 \%)$ & $39(52 \%)$ \\
\hline & & \\
\hline
\end{tabular}

\begin{tabular}{|c|c|c|}
\hline $\begin{array}{c}\text { XI LEGISLATURA } \\
\text { 2016-2020 }\end{array}$ & MUJERES & HOMBRES \\
\hline EAJ/PNV & $14(50 \%)$ & $14(50 \%)$ \\
\hline EH-BILDU & $12(66,6 \%)$ & $6(33,4 \%)$ \\
\hline PSE-EE/PSOE & $6(66,6 \%)$ & $3(33,4 \%)$ \\
\hline PP & $4(44,4 \%)$ & $5(55,6 \%)$ \\
\hline ELKARREKIN PODEMOS & $4(36,3 \%)$ & $7(63,7 \%)$ \\
\hline TOTAL & $40(53,3 \%)$ & $35(46,7 \%)$ \\
\hline
\end{tabular}

Si reparamos en los datos de esta tabla 2 que visualiza los datos por grupos parlamentarios, en la VIII legislatura se produce, con toda probabilidad por la modificación operada en 2005, un aumento muy importante de parlamentarias superando con un 57,3\% la paridad definida en la Ley. Una paridad que también se ve superada en la XI legislatura en la que la presencia de mujeres en el Parlamento asciende al $53,3 \%$. Y tanto en la IX como en la X legislatura asistimos a una bajada de la pre-

(C) UNED. Revista de Derecho Politico

N. ${ }^{\circ} 109$, septiembre-diciembre 2020, págs. 153-189 
sencia de parlamentarias, aunque en ambos casos nos situamos muy cerca de la paridad con una presencia de 32 parlamentarias en la IX legislatura y 36 en la X.

Si acotamos ahora el estudio analítico a lo qué ocurre por Grupos Parlamentarios, podemos aseverar que, en términos absolutos, en la VII Legislatura es el Grupo Parlamentario de EAJ/PNV el que más parlamentarias consigue y el que menos el de UA. Aunque si atendemos a la proporción entre presencia de mujeres y hombres dentro del Grupo es el Grupo Parlamentario Socialista el que logra una mayor presencia de mujeres. Y a partir de la VIII Legislatura el único Grupo Parlamentario que logra o mantener la paridad o una representación de más del $50 \%$ de mujeres es el de $\mathrm{EAJ} / \mathrm{PNV}$. En los casos en los que las parlamentarias han logrado el $100 \%$ de la representación del Grupo se produce cuando solo se logra un escaño. Así ha ocurrido en la VII legislatura con UA y en la VIII con Aralar. Y en polo opuesto situamos a los Grupos Parlamentarios de EB-IU, EA y UPyD sin representación de mujeres el primero ni en la VIII ni en la IX legislatura, el segundo sin ninguna parlamentaria en la IX legislatura y el tercero sin presencia de mujeres ni en la IX ni en la X legislatura.

Realizado el análisis meramente cuantitativo, conviene ahora introducir algún elemento que nos permita observar la realidad desde una perspectiva cualitativa. Para ello, nos fijaremos en la presencia de mujeres en cargos parlamentarios.

TABLA 3: presencia mujeres en órganos rectores en términos absolutos ${ }^{39}$.

\begin{tabular}{|c|c|c|c|c|c|c|c|c|c|c|c|}
\hline $\begin{array}{c}\text { MUJERES CON } \\
\text { CARGO } \\
\text { PARLAMENTARIO }\end{array}$ & $\mathrm{I}$ & II & III & IV & $\mathrm{V}$ & VI & VII & $\begin{array}{l}\text { VIII } \\
2005- \\
2009\end{array}$ & IX & $\mathrm{X}$ & $\mathrm{XI}$ \\
\hline MESA (5 Personas) & 2 & 0 & 1 & 1 & 1 & 2 & 2 & 3 & 2 & 1 & 3 \\
\hline Presidencia & 0 & 0 & 0 & 0 & 0 & 0 & 0 & 1 & 1 & 1 & 1 \\
\hline Vicepresidencia $1^{a}$ & 1 & 0 & 0 & 0 & 0 & 0 & 0 & 1 & 1 & 0 & 1 \\
\hline Vicepresidencia $2^{\mathrm{a}}$ & 0 & 0 & 0 & 0 & 0 & 1 & 0 & 0 & 0 & 0 & 0 \\
\hline Secretaría $1^{\mathrm{a}}$ & 0 & 0 & 1 & 0 & 1 & 0 & 1 & 0 & 0 & 0 & 0 \\
\hline Secretaría $2^{\mathrm{a}}$ & 1 & 0 & 0 & 1 & 0 & 1 & 1 & 1 & 0 & 0 & 1 \\
\hline \multicolumn{12}{|l|}{$\begin{array}{c}\text { JUNTA DE } \\
\text { PORTAVOCES }\end{array}$} \\
\hline Composición total & 7 & 11 & 11 & 11 & 10 & 9 & 9 & 7 & 8 & 7 & 5 \\
\hline Número mujeres & 0 & 0 & 0 & 1 & 0 & 1 & 0 & 1 & 1 & 2 & 1 \\
\hline \multicolumn{12}{|l|}{ COMISIONES } \\
\hline Número Comisiones & 18 & 15 & 13 & 14 & 13 & 15 & 15 & 17 & 20 & 16 & 17 \\
\hline
\end{tabular}

39 Fuente: elaboración propia con datos extraídos de la Web del Parlamento Vasco. 
DEMOCRACIA PARITARIA E IMPACTO DE GÉNERO EN LAS POLÍTICAS...

\begin{tabular}{|c|c|c|c|c|c|c|c|c|c|c|c|}
\hline $\begin{array}{c}\text { MUJERES CON } \\
\text { CARGO } \\
\text { PARLAMENTARIO }\end{array}$ & I & II & III & IV & V & VI & VII & $\begin{array}{c}\text { VIII } \\
2005- \\
2009\end{array}$ & IX & X & XI \\
\hline Presidencia & 1 & 1 & 0 & 2 & 3 & 6 & 7 & 12 & 11 & 9 & 10 \\
\hline Vicepresidencia & 3 & 2 & 2 & 2 & 3 & 5 & 5 & 11 & 6 & 14 & 8 \\
\hline Secretaría & 0 & 3 & 4 & 4 & 8 & 7 & 9 & 12 & 11 & 8 & 10 \\
\hline TOTAL & 6 & 6 & 7 & 10 & 15 & 21 & 23 & 39 & 31 & 34 & 32 \\
\hline
\end{tabular}

Para analizar los datos de la tabla 3, hay que comenzar poniendo de relieve que son los grupos parlamentarios los que deciden la formación de los órganos de la Cámara. Puede observarse que es en la VIII legislatura cuando por primera vez el número de mujeres supera al de parlamentarios en la composición de la Mesa llegando a 3. Un número que, aunque ha descendido a 2 en la IX legislatura y a 1 en la X se mantiene en la XI legislatura. Además, es precisamente en la VIII legislatura cuando por vez primera la Presidencia del Parlamento es asumida por una mujer, algo que se mantiene hasta la actualidad. Y cabe añadir que el cargo dentro de la Mesa que más se ocupa por parlamentarias es el de Secretaría $2^{\mathrm{a}}$.

De los datos presentados y por lo que respecta a la Junta de Portavoces se pueden extraer las siguientes conclusiones. Si bien es en la IV legislatura cuando por primera vez una parlamentaria forma parte de la Junta de Portavoces, en términos porcentuales es en la VIII legislatura cuando observamos que la participación femenina en la Junta ha sufrido un aumento importante llegando al 14\% lo que significa 5 puntos más que en la IV Legislatura en la que la presencia de la única parlamentaria significaba un $9 \%$. Y la tónica general ha sido la de aumentar la presencia de parlamentarias que integran la Junta de portavoces llegando a un $28,5 \%$ en la X legislatura, un porcentaje que baja en la XI a un $20 \%$.

A continuación, nos resta observar la participación de mujeres en las Comisiones. También en el caso de las Comisiones de la VII a la VIII legislatura se aprecia un aumento importante de la presencia de las mujeres en todos los cargos (Presidencia, Vicepresidencia y Secretaría), siendo el aumento más destacable el que se produce en la Vicepresidencia pasando de 5 a 11 las vicepresidencias ostentadas por mujeres en la VIII legislatura, seguido de la Secretaría y de la Presidencia. En concreto, en 2005 de las 17 comisiones existentes, en 12 casos la presidencia la ostentan mujeres siendo esta la cifra más alta de toda la serie, existen 11 vicepresidentas y son 12 las secretarías ocupadas por parlamentarias lo que también constituye el número más elevado de secretarias ostentadas por mujeres desde la constitución del Parlamento. Un aumento generalizado de presencia de parlamentarias en las Comisiones que es la tónica desde la VIII legislatura hasta ahora.

Siguiendo en el ámbito de las Comisiones, observamos que, aunque es en la V legislatura cuando por primera vez todos los cargos están ostentados por mujeres lo

(C) UNED. Revista de Derecho Politico

N. ${ }^{\circ} 109$, septiembre-diciembre 2020, págs. 153-189 
que ocurre solo en una de las Comisiones ${ }^{40}$, es en la VIII legislatura cuando se produce un aumento importante siendo 7 el número de Comisiones en las que todos los cargos están ocupados por parlamentarias ${ }^{41}$. Una cifra que sufre un descenso importante en la IX legislatura en la que solo en 3 Comisiones todos los cargos los ostentan parlamentarias $^{42}$, cifra que pasa a 4 en la X legislatura ${ }^{43}$ y a 5 en la XI legislatura ${ }^{44}$. Así pues, a partir de la VII legislatura en las comisiones el número de mujeres que ostentan la presidencia, vicepresidencia y secretaria aumenta de manera significativa.

Las Comisiones más feminizadas en cuanto a ocupación de cargos parlamentarios son la de Educación, Trabajo, Empleo, Sanidad, Políticas Sociales e Igualdad. Así pues, la presencia de mujeres en órganos directivos de las comisiones aumenta en aquellas relativas a sectores feminizados.

Para ir finalizando, decir que hay que esperar hasta la VIII legislatura para poder apreciar un aumento considerable de mujeres con cargo parlamentario en el Parlamento Vasco, lo que sin duda alguna puede ser imputable a la modificación de la Ley en 2005.Avalan esta afirmación los siguientes datos: son 39 el número de parlamentarias que ostentan cargo parlamentario, lo que supone un aumento de 16 puntos respecto a la legislatura anterior en la que son 23 las mujeres que ocupan cargos. Una tónica que se mantiene hasta la XI legislatura, aunque es cierto que se ha reducido el número de mujeres que ostentan cargo parlamentario si bien estamos ante una reducción insignificante.

En síntesis, la incorporación de las cuotas en la Ley del 2005 ha impactado positivamente en la presencia de mujeres en la Asamblea legislativa desde la perspectiva cualitativa. En 2005 es la primera vez que la presidencia del Parlamento la ostenta una mujer -lo que también ocurre en la XI legislatura-. Es la primera vez que el número de mujeres es mayor que el de parlamentarios en la composición de la Mesa. Asimismo, en esa legislatura la presencia de mujeres en términos porcentuales en la Junta de Portavoces aumenta de forma significativa, aumenta también la presencia de mujeres en la Presidencia, Vicepresidencia y Secretarías de las Comisiones, es la legislatura con mayor número de Comisiones en las que todos los cargos recaen en

40 En concreto, así ocurre en el caso de la Comisión de Trabajo y Sanidad.

41 Es el caso de las siguientes Comisiones: Educación y Cultura; Urgencia legislativa, Reglamento y Gobierno; Trabajo y Acción social; Agricultura y Pesca; Asuntos Europeos y Acción Exterior; y Sanidad; y Comisión de Mujer y Juventud.

42 Se trata de las Comisiones de Economía, Hacienda y Presupuestos; la de Derechos Humanos y Solicitudes Ciudadanas; y la de Estudios sobre duplicidades e ineficiencias existentes en el entramado institucional vasco.

43 Nos referimos a las siguientes 4 Comisiones: de Hacienda y Presupuestos; de Medio Ambiente y Política Territorial; de Empleo, Política Sociales y Vivienda; y de Asuntos Europeos y Acción Exterior.

44 En la XI legislatura todos los cargos son ostentados por mujeres en las siguientes Comisiones: Educación; Derechos Humanos e Igualdad; control de EITB; Comercio, Consumo y Turismo; y en la de investigación del proceso de adjudicación de la prestación de los servicios de comedores escolares de gestión directa del Gobierno Vasco desde el año 2003 y responsabilidades políticas derivadas. 
parlamentarias y es la legislatura VIII en la que tenemos un mayor número de mujeres con cargo parlamentario.

Analizada cuál es la situación en el Parlamento abordaremos ahora el análisis respecto al Gobierno Vasco. Optamos por diferenciar las 2 siguientes etapas: la que abarca desde la constitución del Gobierno vasco de la I Legislatura hasta 20055; y, desde el 2005 hasta la actualidad ${ }^{46}$. Un año en el que, como hemos señalado, mediante la reforma de la Ley de Gobierno se exige que en el mismo ambos sexos estén representados al menos en un $40 \%$.

TABLA 4: cargos ocupados por mujeres en el Gobierno Vasco hasta la VII legislatura $(2005)^{47}$.

\begin{tabular}{|c|c|c|c|c|c|c|c|}
\hline CARGO & $\begin{array}{c}1980- \\
1984\end{array}$ & $\begin{array}{c}1984- \\
1987^{48}\end{array}$ & $\begin{array}{c}1987- \\
1991\end{array}$ & $\begin{array}{c}1991- \\
1995^{49}\end{array}$ & $\begin{array}{c}1995- \\
1999\end{array}$ & $\begin{array}{c}1999- \\
2001\end{array}$ & $\begin{array}{c}2001- \\
2005\end{array}$ \\
\hline LEHENDAKARITZA & $\mathrm{H}^{50}$ & $\mathrm{H}^{51}$ & $\mathrm{H}^{52}$ & $\mathrm{H}^{53}$ & $\mathrm{H}$ & $\mathrm{H}$ & $\mathrm{H}$ \\
\hline $\begin{array}{c}\text { CONSEJERIAS } \\
\text { MUJERES }\end{array}$ & 0 & 0 & 0 & 1 & 3 & $1^{54}$ & $4^{55}$ \\
\hline $\begin{array}{c}\text { CONSEJERIAS } \\
\text { HOMBRES }\end{array}$ & 14 & 10 & 15 & 12 & 12 & 9 & 7 \\
\hline
\end{tabular}

45 Debido a la dificultad de lograr datos de estos años, en este caso la muestra la ceñimos a los cargos de lehendakaritza y consejerías.

46 En esta segunda etapa, el análisis se hará teniendo en cuenta los datos relativos a la Lehendakaritza, Consejerías y Viceconsejerias.

47 Fuente: elaboración propia con datos extraídos de la Web del Gobierno Vasco.

48 El Gobierno de la II Legislatura se conformó en abril de 1984 y cesó en sus funciones el 27 de enero de 1985. En el cuadro se han reflejado los datos del Gobierno conformado en 1984, ello no obstante en el Gobierno que sucedió a este hasta completar la II legislatura tampoco ninguna mujer ostentaba cargo alguno.

49 El Gobierno de la IV Legislatura que se conformó en febrero de 1991 cesó en sus funciones en octubre del mismo año. En el cuadro se han reflejado los datos del Gobierno conformado en febrero, y en el Gobierno que sucedió a este de coalición EAJ-PNV-PSE-EE/PSOE hasta completar la legislatura también una mujer ostentaba una Consejería, en concreto, la de Comercio, Consumo y Turismo.

50 En esta I Legislatura se contempla la Vicepresidencia para el desarrollo estatutario ocupada, asimismo, por un hombre.

51 En esta II legislatura hay una Vicepresidencia ocupada también por un hombre.

52 En esta III Legislatura hay además una Vicepresidencia, una secretaria de la Presidencia y una Secretaria de la Presidencia del Gobierno, también, ocupadas por hombres los 3 cargos.

53 En esta Legislatura también se nombra una Secretaría de Presidencia ocupada por un hombre.

54 La Consejera de Hacienda y Administración pública también ostenta el cargo de vicepresidenta del Gobierno.

55 Son 4 Consejerías ocupadas por mujeres, pero además 1 de ellas es la Portavoz del Gobierno y otra la vicepresidenta del Gobierno.

(C) UNED. Revista de Derecho Político

N. ${ }^{\circ} 109$, septiembre-diciembre 2020, págs. 153-189 
Desde la conformación del primer Gobierno Vasco en 1980 hasta la modificación de la Ley de Gobierno en 2005 en la que se incorpora la obligatoriedad de la representación de ambos sexos al menos en un $40 \%$ la presencia de mujeres en el ejecutivo vasco brilla por su ausencia en las 3 primeras legislaturas, siendo en la IV la primera vez que una consejería es ocupada por una mujer. En concreto, se trata de la Consejería de Economía y Planificación en el Gobierno que se conformó en la primera parte de la legislatura y de la Consejería de Comercio, Consumo y Turismo en el caso del Gobierno de coalición que se constituyó hasta el final de la Legislatura. También en la VI legislatura solo 1 mujer forma parte del Ejecutivo, pero en este caso la Consejera de Hacienda y Administración pública también ocupa el cargo de vicepresidenta del Ejecutivo.

Y durante esta primera etapa es en la VII legislatura donde se aprecia un aumento considerable de mujeres con cargo en el Gobierno. Son 4 las consejerías ocupadas por mujeres siendo, además, una de ellas la que ostenta la Vicepresidencia del Gobierno al igual que en la VI Legislatura. En concreto, en la VII Legislatura son mujeres las que ocupan: la Vicepresidencia y Consejería de Hacienda y Administración Pública; la Consejería de Educación, Universidades e Investigación; la consejería de Industria, Comercio y Turismo; y la Consejería de Cultura quien ostenta asimismo la portavocía del Gobierno.

Esto por lo que respecta a la presencia de mujeres en términos absolutos, pero si fijamos la mirada en lo que ocurre en términos porcentuales observamos que el porcentaje más alto de presencia de mujeres que ocupan consejerías se da en la VII legislatura con un 36,3\% de presencia femenina y el más bajo en la IV donde la presencia de mujeres supone un $8,8 \%$.

Para ir cerrando el análisis de los datos que arroja la tabla 4 , se constata que el cargo que parece absolutamente impermeable a las mujeres es el de Lehendakaritza del Gobierno Vasco y se han tenido que esperar casi 20 años para que una mujer haya accedido a la Vicepresidencia del Gobierno Vasco. En suma, en esta primera etapa se evidencia con claridad la ausencia de las mujeres en la esfera política vasca.

TABLA 5: cargos ocupados por mujeres en el Gobierno Vasco a partir de la VIII legislatura $(2005)^{56}$.

\begin{tabular}{|c|c|c|c|c|}
\hline CARGO & $2005-2009$ & $2009-2012$ & $2012-2016$ & $2016-2020$ \\
\hline LEHENDAKARITZA & 0 & 0 & 0 & 0 \\
\hline
\end{tabular}

56 Fuente: elaboración propia con datos extraídos de la Web del Gobierno Vasco y de los siguientes informes: «Cifras sobre la participación social y política de las mujeres y hombres en Euskadi» (Emakunde 2005); «La presencia de mujeres y hombres en los ámbitos de toma de decisión en Euskadi» (Emakunde 2008); y «Cifras. Mujeres y hombres en Euskadi» (Emakunde, 2010). 
DEMOCRACIA PARITARIA E IMPACTO DE GÉNERO EN LAS POLÍTICAS...

\begin{tabular}{|c|c|c|c|c|}
\hline CONSEJERIAS & $\begin{array}{c}5 \mathrm{M}^{57}(45,4 \%) \\
6 \mathrm{H}(54,6 \%)\end{array}$ & $\begin{array}{c}5 \mathrm{M}(50 \%) \\
5 \mathrm{H}(50 \%)\end{array}$ & $\begin{array}{c}4 \mathrm{M}(50 \%) \\
4 \mathrm{H}(50 \%)\end{array}$ & $\begin{array}{c}7 \mathrm{M}(63,6 \%) \\
4 \mathrm{H}(36,4 \%)\end{array}$ \\
\hline \multirow{2}{*}{ VICECONSEJERIAS } & $4 \mathrm{M}(11,1 \%)$ & $12 \mathrm{M}^{58}(34,3 \%)$ & $9 \mathrm{M}^{59}(31 \%)$ & $14 \mathrm{M}(51,8 \%)$ \\
& $32 \mathrm{H}(88,9 \%)$ & $23 \mathrm{H}(65,7 \%)$ & $20 \mathrm{H}(69 \%)$ & $13 \mathrm{H}(48,2 \%)$ \\
\hline TOTAL MUJERES & $9(18,75 \%)$ & $17(36,9 \%)$ & $13(34,2 \%)$ & $21(53,8 \%)$ \\
\hline
\end{tabular}

La primera impresión que produce una simple mirada a los datos que aparecen en la tabla 5 es que resulta evidente el techo de cristal con el que se topan las mujeres puesto que nunca ha existido una Lehendakari.

Fijada la mirada en cada una de las legislaturas, observamos que en la VIII legislatura que arranca en 2005 las Consejerías encabezadas por mujeres son las siguientes: Hacienda y Administración Pública; Industria, Comercio y Turismo; Cultura; Medio Ambiente y Ordenación del Territorio; y Transportes y Obras Públicas. En consecuencia, se respeta por primera vez la presencia equilibrada entre mujeres y hombres lo que sin duda alguna se debe a la obligatoriedad introducida en la Ley del Gobierno en el 2005. Una presencia equilibrada que por otra parte está muy lejos de conseguirse en el nivel de viceconsejerias. Es el Departamento de Cultura en el que más mujeres ocupan altos cargos con una presencia paritaria de mujeres y hombres ( 7 y 7 respectivamente) siendo el Departamento con mayor diferencia el de Agricultura, Pesca y Alimentación donde ninguna sola mujer ocupa Alto Cargo frente a los 11 hombres seguido del de Medio Ambiente y Ordenación del Territorio con 1 mujer como Alto Cargo frente a 9 hombres $^{60}$.

Las principales ideas que se extraen de los datos de la IX legislatura es que se logra la paridad en cuanto a la presencia de mujeres y hombres en las Consejerías mejorándose la previsión de la presencia equilibrada legalmente contemplada. Las Consejerías encabezadas por mujeres son las de: Interior, Justicia y Administración Pública; Educación, Universidades e Investigación; Empleo y Asuntos Sociales; Medio Ambiente, Planificación Territorial, Agricultura y Pesca; y Cultura. Y asimismo se produce un aumento reseñable de mujeres en las Viceconsejerías pasándose de 3 de la VIII legislatura a un total de 12 . Y solo en 4 Viceconsejerías no se respeta la representación equilibrada. Es el Departamento de Industria, Innovación Comercio y Turismo en el que más mujeres ocupan Altos Cargos ( 7 frente a 11 hombres) y el

57 Además, la Consejera de Hacienda y Administración Pública es la vicepresidenta del Gobierno y la Consejera de Cultura asume también la portavocía del Gobierno.

58 Los datos desagregados referentes a las Viceconsejerias en la IX Legislatura se extraen del informe de Emakunde: «Seguimiento del cumplimiento, desarrollo y aplicación de la Ley 4/2005, de 18 de febrero, para la igualdad de mujeres y hombres» de 2011.

59 Los datos desagregados de las Viceconsejerias en la X Legislatura son extraídos del informe de Emakunde: «Evaluación cuantitativa de la Ley 4/2005 para la igualdad de mujeres y hombres en la CAE» de 2015 .

60 Los datos referentes a la mayor o menor presencia de mujeres en los diferentes Departamentos han sido extraídos de los Informes de Emakunde ya referenciados.

(C) UNED. Revista de Derecho Politico

N. ${ }^{\circ} 109$, septiembre-diciembre 2020, págs. 153-189 
Departamento con mayor brecha en cuanto a número de Altos cargos ocupados por mujeres y hombres es el de Medio Ambiente, Planificación Territorial, Agricultura y Pesca $^{61}$.

La X Legislatura (2012-2016) se caracteriza por la paridad absoluta que se aprecia en el nivel de las Consejerías, con igual número de Consejerías presididas por mujeres que por hombres ( 4 y 4). Las Consejerías encabezadas por mujeres son las de: Desarrollo Económico y Competitividad; Educación, Política Lingüística y Cultura; Seguridad; y Medio Ambiente y Política territorial. Ahora bien, esa distribución paritaria no se da a nivel de Viceconsejerías, ya que solo el $31 \%$ de las mismas están dirigidas por mujeres frente a un $69 \%$ encabezadas por hombres. Por lo tanto, es apreciable un ligero retroceso en cuanto a las Viceconsejerías respecto a lo avanzado en la anterior legislatura. En concreto, la presencia de viceconsejerías encabezadas por mujeres ha descendido en algo más de 3 puntos porcentuales.

Situados ahora en la XI legislatura, por un lado, resulta apreciable una mejora de la presencia de mujeres en las Consejerías pasando de 4 a 7 las que son encabezadas por mujeres: la de Desarrollo Económico e Infraestructuras; la de Empleo y Políticas Sociales; la de Educación; la relativa a Salud; la de Turismo, Comercio y Consumo; la de Seguridad; y finalmente la de Trabajo y Justicia. De modo que con un 63,6\% de Consejerías encabezadas por mujeres la balanza se inclina a favor estas. Y, por otro lado, también es la primera vez que el número de viceconsejerías ocupadas por mujeres supera al de las ocupadas por hombres. En fin, con un 53,8\% es esta última legislatura la única en la que las mujeres que ocupan Altos Cargos dentro del Gobierno Vasco supera al número de hombres.

Por último, está claro que la modificación de la Ley de Gobierno en 2005 ha tenido un efecto positivo desde una perspectiva cuantitativa puesto que en todos los Altos Cargos se ha reducido la distancia de género — siendo en la XI legislatura la presencia de mujeres de un 53,8\%-, salvo un pequeño retroceso en el caso de las viceconsejerías en la X legislatura. En el caso de las Consejerías es donde más palpable es el aumento de la presencia de mujeres pasándose de un $50 \%$ de la IX y X Legislatura a un 63,6\% en la XI. Por el contrario, donde más acuciante es la brecha es en el caso de las Viceconsejerias hasta la X legislatura, una situación que da un giro en la XI Legislatura siendo más mujeres que hombres las que encabezan las distintas Viceconsejerías. Y recordemos que, es la Presidencia del Gobierno Vasco el cargo absolutamente impermeable a las mujeres.

${ }^{61}$ Datos extraídos del Informe de Emakunde «Seguimiento del cumplimiento, desarrollo y aplicación de la Ley 4/2005, de 18 de febrero, para la Igualdad de mujeres y hombres» de 2011. 


\subsection{La evaluación del impacto de género en las políticas públicas autonómicas ${ }^{62}$}

La evaluación del impacto de género (en lo sucesivo, EIG) pretende incorporar sistemáticamente la perspectiva de género en las políticas públicas y permite, -partiendo de la idea del carácter sistémico de la desigualdad de género-, realizar un análisis ex ante de todas las actuaciones en materia de políticas públicas durante el período de preparación de la norma o acto. La EIG se configura como una técnica analítica que permite analizar la realidad y adoptar decisiones informadas y más comprometidas con la igualdad. La Exposición de Motivos de la Ley 3/2007, de 22 de marzo, para la Igualdad Efectiva de Mujeres y Hombres considera estos informes como instrumentos básicos para el logro de la igualdad efectiva intergéneros.

Antes de avanzar, subrayar que en el presente trabajo no se trata de hacer un análisis del instrumento o de la herramienta per se — a saber, de la EIG en sí misma considerada ${ }^{63}$-.Lo que se persigue es determinar si existe alguna relación entre presencia de mujeres en los órganos decisorios a nivel autonómico y el mayor impacto en el proceso legislativo y/o de elaboración de las políticas públicas desde el punto de vista del género. Se trata de ver si el sistema de cuotas y la mayor presencia de mujeres en los centros de toma de decisión política repercute positivamente en la consecución de la igualdad entendiendo que su logro pasa por el diseño y la materialización de políticas públicas con perspectiva de género, lo que exige analizar la EIG $^{64}$. Para contribuir al propósito perseguido observaremos la EIG en tanto esta constituye un indicador para testar el impacto que la presencia de mujeres en la política despliega sobre las políticas públicas desde la óptica del género.

La regulación a nivel autonómico de la EIG se produce en la Ley 4/2005. Una exigencia a la que también alude el Comité de la CEDAW quién pide a España que responda a la exigencia de la $E I^{65}$. Como consecuencia de tal exigencia, la Ley 30/2003, de 13 de octubre, sobre medidas para incorporar la valoración del impacto de género en las disposiciones normativas que elabore el Gobierno modificó los arts. 22.2 y 24.1.b) de la Ley 50/1997, de 27 de noviembre, del Gobierno incorporando, así, la obligatoriedad de tal evaluación de impacto.

En particular, el art. 19.1 de la Ley del 2005 establece que: «Antes de acometer la elaboración de una norma o acto administrativo, el órgano administrativo que lo

62 Apartado elaborado, principalmente, siguiendo los datos que aparecen en el informe «Evaluación de los procesos de evaluación previa del impacto en función del género en la elaboración de normativa en la CAE 2015», Emakunde, Vitoria-Gasteiz, 2017.

63 Para un análisis pormenorizado sobre las fortalezas, debilidades, logros o desafíos de la EIG consúltese, el exhaustivo informe de Emakunde «Evaluación de los procesos de evaluación previa del impacto en función del género en la elaboración de normativa en la CAE 2015», Vitoria- Gasteiz, 2017.

${ }_{64}$ No obstante, somos conscientes de las limitaciones que presenta la EIG puesto que las cuestiones de carácter estructural y la revisión de los enfoques de intervención desde una perspectiva de género exceden del ámbito del alcance de tales evaluaciones.

${ }_{65} \mathrm{~N}^{\circ} 24$ de las Observaciones finales de la CEDAW/C/ESP/CO/609-46099. Vid en este sentido, asimismo, la Directiva 2002/73/CEE y, en concreto, su art. 2.3.

(C) UNED. Revista de Derecho Politico

N. ${ }^{\circ} 109$, septiembre-diciembre 2020, págs. 153-189 
promueva ha de evaluar el impacto potencial de la propuesta en la situación de las mujeres y en los hombres como colectivo. Para ello, ha de analizar si la actividad proyectada en la norma o acto administrativo puede tener repercusiones positivas o adversas en el objetivo global de eliminar las desigualdades entre mujeres y hombres y promover su igualdad». Y es el apartado segundo el que prevé que será el Gobierno Vasco el que, a propuesta de Emakunde, apruebe tanto las pautas que han de observarse para la realización de la evaluación previa del impacto de género como las normas o actos administrativos que quedan excluidos de la necesidad de ser sometidos a esta evaluación.

Es necesario subrayar la importancia de estos informes de evaluación que, servirán, aun con ciertas limitaciones, en palabras de J. M. Gil Ruiz para «desmontar la ilusa y perversa creencia de que las normas jurídicas son neutras» ${ }^{66}$. Y a la vez para detectar aquellas políticas que servirán para modificar las relaciones de subordiscriminación en las que se sitúa a las mujeres y trasformar así la sociedad evitando la perpetuación de las desigualdades existentes. En suma, la integración de la perspectiva de género es una estrategia que servirá para lograr la igualdad real entre mujeres y hombres de ahí la trascendencia de estos informes de evaluación del impacto de género.

En concreto fue en el 2007 mediante Acuerdo del Consejo de Gobierno de 13 de febrero de 2007, cuando se aprueban las Directrices para la realización de la evaluación del impacto en función del género y la incorporación de medidas para eliminar desigualdades y promover la igualdad de mujeres y hombres ${ }^{67}$. Unas Directrices que son modificadas en el año 2012 a través de la Resolución 40/2012, de 21 de agosto, de la directora de la Secretaría del Gobierno y de Relaciones con el Parlamento ${ }^{68}$. Estas modificaciones fueron adoptadas de común acuerdo con Emakunde y se reducen básicamente a las 2 siguientes: se concretan de forma más definida las normas y actos administrativos exentas de la realización del informe de impacto en función del género, incorporándose la posibilidad de justificar la no pertinencia de género en los proyectos de norma que deberá argumentarse y verificarse por parte de Emakunde ${ }^{69}$; y se simplifica el Informe en lo relativo a su estructura y contenido. Así pues, la modificación responde a la necesidad de dotar de una mayor transparencia y agilidad

66 GIL RUIZ, J.M (2012)., «Los informes de Evaluación de Impacto de género (IEIG) como garantía del gender mainstreaming y su incidencia en la normativa y jurisprudencia española», Revista Vasca de Administración Pública, núm. 92, enero-abril, p. 17.

${ }_{67}$ Resolución 5/2007, de 14 de febrero, del Director de la Secretaría del Gobierno y de Relaciones con el Parlamento.

68 BOPV de 25 de septiembre de 2012.

69 Una información más detallada en ALONSO GARCÍA, C. (2020), «País Vasco» en CANALS AMETLLER, D. (Dirs.), La evaluación de impacto normativo por razón de género. Su aplicación efectiva en las instituciones europeas y en España, Madrid, Centro de Estudios Políticos y Constitucionales, principalmente, pp. 297-299. 
al procedimiento ${ }^{70}$. Y resulta nuclear en este aspecto, también la Guía para la elaboración de informes de impacto de género publicada por Emakunde en el $2013^{71}$.

Por lo que concierne al ámbito de aplicación de la EIG están sujetos al requerimiento de realización del informe del impacto de género: con carácter general, todos los proyectos de disposiciones de carácter general. Entiéndase los proyectos de normas jurídicas con rango de ley o reglamento. Y, también, las propuestas de actos administrativos relativas a convocatorias de ofertas públicas de empleo público y concursos de traslados.

En las próximas páginas expondremos, de forma descriptiva, los datos más relevantes acerca de la evaluación del impacto de género en las políticas públicas en el caso del País Vasco desde la VIII Legislatura que es cuando se aprueban las Directrices para su realización.

TABLA 6: número de informes de impacto emitidos por los Departamentos desde la VIII legislatura y número de mujeres con cargo en el Gobierno Vasco ${ }^{72}$.

\begin{tabular}{|c|c|c|c|c|}
\hline Legislatura & VIII & IX & X & XI \\
\hline Número de informes emitidos & 216 & 175 & 191 & 113 \\
\hline Número de mujeres con cargo & $9(18,75 \%)$ & $17(36,9 \%)$ & $13(34,2 \%)$ & $21(53,8 \%)$ \\
\hline
\end{tabular}

Resulta difícil extraer conclusiones determinantes puesto que, por un lado, el volumen de informes de impacto emitidos en las diferentes legislaturas puede sufrir oscilaciones importantes en función de la producción normativa de cada legislatura. Y, por otro lado, la realización de informes de impacto no siempre denota voluntad de articular políticas públicas con impacto de género puesto que la obligatoriedad de estos los convierte, a veces, en una mera formalidad.

Aun así y sin perjuicio de todas las necesarias reservas, observamos que: curiosamente es en el VIII legislatura cuando se ha emitido el mayor volumen de informes de impacto de género por los distintos Departamentos gubernamentales. Algo que llama la atención puesto que es a mitad de legislatura cuando se empiezan a emitir tales informes una vez aprobadas las Directrices del año 2007. Y, también llama la atención que conforme aumenta el número de mujeres que ocupan cargos en el Ejecutivo autonómico desciende el número de informes de impacto emitidos. Así en la XI legislatura con más del $50 \%$ de mujeres en el Gobierno el número de informes ha descendido casi a la mitad que en el VIII legislatura en la que el número de mujeres al frente de las Consejerías y Viceconsejerías no alcanza ni el $20 \%$.

70 Para una mayor concreción, puede consultarse la citada Resolución 40/2012.

71 De particular interés resulta, también, la Guía para la Evaluación del Impacto de Género que elaboró la Comisión en el marco del IV Programa de Acción Comunitaria para la Igualdad de oportunidades entre hombres y mujeres 1996-2000.

72 Fuente de elaboración propia con datos facilitados por Emakunde. 
TABLA 7: informes de impacto emitidos por los Departamentos en cada legislatura desde la $\mathrm{VIII}^{73}$.

\begin{tabular}{|c|c|c|}
\hline $\begin{array}{c}\text { VIII legislatura } \\
\text { 2005-2009 }\end{array}$ & $\begin{array}{c}\text { Número informes } \\
\text { emitidos por los } \\
\text { Departamentos }\end{array}$ & $\begin{array}{c}\text { Número de mujeres con } \\
\text { Cargo en el } \\
\text { Departamento }\end{array}$ \\
\hline Presidencia & 0 & 0 \\
\hline $\begin{array}{c}\text { Vicepresidencia, Hacienda y } \\
\text { Administración Pública }\end{array}$ & 14 & 1 \\
\hline Justicia, Empleo y Seguridad Social & 36 & 1 \\
\hline Interior & 14 & 2 \\
\hline Industria, Comercio y Turismo & 15 & 1 \\
\hline Vivienda y Asuntos Sociales & 27 & 0 \\
\hline Educación, Universidades e & 74 & 2 \\
\hline Investigación & 4 & 1 \\
\hline Sanidad & 16 & 0 \\
\hline Medio Ambiente y Ordenación \\
Territorio
\end{tabular}

\begin{tabular}{|c|c|c|}
\hline $\begin{array}{c}\text { IX Legislatura } \\
\text { 2009-2012 }\end{array}$ & $\begin{array}{c}\text { Número de informes } \\
\text { emitidos por los } \\
\text { Departamentos }\end{array}$ & $\begin{array}{c}\text { Número de mujeres con } \\
\text { cargo en el } \\
\text { Departamento }\end{array}$ \\
\hline Presidencia & 8 & 0 \\
\hline $\begin{array}{c}\text { Interior, Justicia y Administración } \\
\text { Pública }\end{array}$ & 36 & 0 \\
\hline Economía y Hacienda & 13 & 1 \\
\hline $\begin{array}{c}\text { Industria, Innovación, Comercio y } \\
\text { Turismo }\end{array}$ & 31 & 0 \\
\hline Vivienda, Obras Públicas, y Transporte & 9 & \\
\hline
\end{tabular}

73 Fuente de elaboración propia con datos facilitados por Emakunde.

74 Nos referimos a nivel de Consejería y Viceconsejerías.

75 Nos ha sido imposible conseguir los datos relativos a las Viceconsejerías ocupadas por mujeres, por ello en la tabla solo aparecen datos de las Consejerías. 
DEMOCRACIA PARITARIA E IMPACTO DE GÉNERO EN LAS POLÍTICAS...

\begin{tabular}{|c|c|c|}
\hline $\begin{array}{c}\text { IX Legislatura } \\
\text { 2009-2012 }\end{array}$ & $\begin{array}{c}\text { Número de informes } \\
\text { emitidos por los } \\
\text { Departamentos }\end{array}$ & $\begin{array}{c}\text { Número de mujeres con } \\
\text { cargo en el } \\
\text { Departamento }\end{array}$ \\
\hline $\begin{array}{c}\text { Educación, Universidades e } \\
\text { Investigación }\end{array}$ & 138 & 1 \\
\hline Sanidad y Consumo & 11 & 1 \\
\hline $\begin{array}{c}\text { Medio Ambiente, Planificación } \\
\text { territorial, Agricultura y Pesca }\end{array}$ & 29 & 1 \\
\hline Cultura & 11 & 1 \\
\hline Empleo y Asuntos Sociales & 29 & 0 \\
\hline
\end{tabular}

\begin{tabular}{|c|c|c|}
\hline $\begin{array}{c}\text { X legislatura } \\
2012-2016\end{array}$ & $\begin{array}{c}\text { Número de informes } \\
\text { emitidos por los } \\
\text { Departamentos }\end{array}$ & $\begin{array}{c}\text { Número de mujeres con } \\
\text { cargo en el } \\
\text { Departamento }\end{array}$ \\
\hline Presidencia & 8 & 0 \\
\hline Administración Pública y Justicia & 24 & 0 \\
\hline Hacienda y Finanzas & 13 & 1 \\
\hline Seguridad & 12 & 1 \\
\hline $\begin{array}{c}\text { Desarrollo Económico y } \\
\text { Competitividad }\end{array}$ & 30 & 1 \\
\hline Empleo y Políticas Sociales & 20 & 0 \\
\hline Educación, Política Lingüística y \\
Cultura
\end{tabular}

76 Asimismo, en la X legislatura nos ha sido imposible conseguir los datos relativos a las Viceconsejerías ocupadas por mujeres, así en la tabla solo se reflejan los datos referentes a las Consejerías. Ello, no obstante, nos puede dar una pista para hacer la lectura de los datos el hecho de que, según se extrae del Informe de Emakunde «Evaluación cuantitativa de la Ley 4/2005 para la igualdad de mujeres y hombres en la CAE 2015» publicado en el año 2017- en el nivel de viceconsejerías en esta X legislatura los departamentos con mayor grado de igualdad en la presencia de mujeres y hombres son: Educación, Política Lingüista y Cultura; y Desarrollo Económico y Competitividad. Mientras que el Departamento de Hacienda y Finanzas, el de Seguridad y el de Salud estos cargos están ocupados íntegramente por hombres.

(C) UNED. Revista de Derecho Político

181

N. ${ }^{\circ} 109$, septiembre-diciembre 2020, págs. 153-189 


\begin{tabular}{|c|c|c|}
\hline $\begin{array}{c}\text { XI legislatura } \\
\text { 2016-2020 }\end{array}$ & $\begin{array}{c}\text { Número informes } \\
\text { emitidos por los } \\
\text { Departamentos }\end{array}$ & $\begin{array}{c}\text { Número de mujeres con } \\
\text { Cargo en el } \\
\text { Departamento }\end{array}$ \\
\hline $\begin{array}{c}\text { Lehendakaritza } \\
\text { Gobernanza Pública y } \\
\text { Autogobierno }\end{array}$ & 9 & 1 \\
\hline $\begin{array}{c}\text { Desarrollo Económico e } \\
\text { Infraestructuras }\end{array}$ & 13 & 3 \\
\hline Empleo y Políticas Sociales & 9 & 2 \\
\hline $\begin{array}{c}\text { Medio Ambiente, Planificación } \\
\text { Territorial y Vivienda }\end{array}$ & 7 & 2 \\
\hline Hacienda y Economía & 9 & 2 \\
\hline Educación & 45 & 2 \\
\hline Salud & 4 & 1 \\
\hline Turismo, Comercio y Consumo & 6 & 2 \\
\hline Cultura y Política Lingüística & 6 & 2 \\
\hline Seguridad & & 2 \\
\hline Trabajo y Justicia & 4 & 2 \\
\hline
\end{tabular}

A la vista de los datos cuantitativos y cualitativos expuestos, en la VIII legislatura es el Departamento de Educación, Universidades e Investigación el que ha emitido un mayor volumen de Informes seguido del de Justicia, Empleo y Seguridad Social y ocupando el tercer puesto el de Vivienda y Asuntos Sociales en el que ninguna mujer ocupa cargo alguno. En cambio, si obviamos el caso de la Presidencia que no ha emitido informe alguno, el Departamento que se sitúan en la cola con solo 2 informes emitidos es el de Transporte y Obras Públicas al frente de cuya Consejería está una mujer.

Asimismo, en la IX Legislatura es el Departamento de Educación, Universidades e Investigación -liderado por una consejera- el que ocupa el primer puesto del ranking en cuanto a informes emitidos y también son mujeres quienes están al frente de los Departamentos que se sitúan en segundo y tercer lugar. A su vez, de los 4 Departamentos que menos informes han emitido en tres de ellos ninguna mujer ocupa la Consejería.

77 En esta XI Legislatura los datos se refieren a Consejerías y Viceconsejerías y han sido extraídos de la Web del Gobierno Vasco.

78 En el caso de Lehendakaritza se han tomado en cuenta que de 3 Secretarías Generales solo 1 de ellas está encabezada por una mujer. 
Por lo que respecta a la X Legislatura es el ámbito sectorial relativo a la Educación -que en la X legislatura se inserta en el mismo Departamento que Política Lingüística y Cultura- el que, igualmente, ha emitido el mayor número de informes de impacto con un total de 74, seguido del de Desarrollo Económico y Competitividad con 30 informes emitidos. Y son estos los 2 Departamentos con mayor grado de igualdad en la presencia de mujeres y hombres. En cambio, el Departamento de Hacienda y Finanzas, y el de Salud en los que las Consejerías y viceconsejerias están ocupadas íntegramente por hombres son de los que menos informes han emitido. Aunque lo cierto es que, por ejemplo, el Departamento de Seguridad liderado por una mujer ha emitido menos informes que el de Hacienda y Finanzas.

Queda referirnos a la situación de la actual legislatura, a saber: la XI. Se mantiene la tónica de las anteriores, por lo que respecta al hecho de que es el Departamento de Educación el más prolífero en cuanto a emisión de informes de impacto de género y ello aun cuando no es este el Departamento en el que encontramos mayor presencia de mujeres con cargo. Cierto es que el Departamento que cuenta con más mujeres al frente de la Consejería o Viceconsejerías es el segundo Departamento en cuanto al número de informes emitidos, en concreto, nos referimos al de Desarrollo Económico e Infraestructuras, pero igualmente cierto resulta que los Departamentos con menor presencia de mujeres - léase Departamento de Hacienda y Economía o el de Gobernanza Pública y Autogobierno- no son los que menos informes han emitido

En consecuencia, no estamos en condiciones de aseverar la hipótesis de que una mayor presencia de mujeres con cargo en los Departamentos gubernamentales suponga un mayor volumen de informes de impacto de género, $y$, por ende, que esa presencia asegure el diseño y materialización de políticas públicas con perspectiva de género. Esto es, no existe una relación de causalidad entre mayor presencia de mujeres y más volumen de informes de impacto. En fin, no podemos aseverar que el hecho de que haya mujeres que ocupen cargos en el Gobierno Vasco permita incidir políticamente a la hora de plantear políticas públicas con perspectiva de género capaces de lograr una sociedad más igualitaria. Hace falta por tanto seguir avanzando para que la participación política de las mujeres permita alcanzar una verdadera Representación sustantiva ${ }^{79}$.

Y para ir finalizando, por un lado, el volumen de informes de impacto de género emitidos no depende solamente de una mayor presencia política de mujeres en cargos. Entre otros elementos, influye en ello de manera determinante la experticia del personal del Departamento encargado de realizar tales informes, la desigual producción normativa de los Departamentos, o el tipo de Departamento. Y, por otro lado, la realización de los informes de género dado su preceptividad tampoco es indicador

79 DIZ, I. y LOIS, M. diferencian entre los conceptos de Representación Descriptiva y Representación Sustantiva (DIZ, I. y LOIS, M. (2012) ¿Han conquistado las mujeres el poder político? Un análisis de su representación política en las instituciones autonómicas, Madrid, Catarata, pp. 23-25).

(C) UNED. Revista de Derecho Politico

N. ${ }^{\circ} 109$, septiembre-diciembre 2020, págs. 153-189 
irrefutable del potencial transformador de la norma puesto que, en muchos casos, el informe se convierte en una mera rutina que debe ser cumplimentada.

\subsection{Las iniciativas parlamentarias y gubernamentales en materia de igualdad}

Las iniciativas impulsadas por el ejecutivo autonómico y las iniciativas parlamentarias también constituyen un indicador para valorar de qué manera impacta, o si irradia un impacto positivo desde la perspectiva de género, la presencia de mujeres en las políticas públicas que se diseñan y se materializan.

Según los datos que arroja la actual legislatura ${ }^{80}$, observamos que por lo que respecta a la actividad del Ejecutivo autonómico el grueso de las iniciativas en materia de igualdad adoptan la forma de resolución y su fuente es la Dirección de Emakunde. Un dato a todas luces absolutamente lógico. Asimismo, Lehendakaritza ha sido el órgano emisor de 2 Decretos ambos del año 2017 y ambos referentes al cese y nombramiento, respectivamente, de la Secretaría General de Emakunde-Instituto Vasco de la Mujer ${ }^{81}$. Centrándonos en la actividad de los Departamentos nos encontramos con la realidad que muestra la siguiente tabla.

TABLA 8. Disposiciones emitidas en la XI legislatura por el Gobierno autonómico en materia de igualdad ${ }^{82}$.

\begin{tabular}{|c|c|c|c|c|}
\hline XI Legislatura & 2017 & 2018 & 2019 & 2020 \\
\hline Dpto. de Gobernanza Pública y Autogobierno & 3 & 2 & & 3 \\
\hline Dpto. de Empleo y Políticas Sociales & 2 & 1 & 1 & \\
\hline Dpto. de Cultura y Política Lingüística & 3 & 4 & 3 & \\
\hline Dpto. de Educación & & 2 & 2 & \\
\hline Dpto de Hacienda y Economía & & 1 & & \\
\hline Número de disposiciones & 8 & 10 & 6 & 3 \\
\hline
\end{tabular}

Partiendo de los datos mencionados, observamos que el Departamento más activo en esta legislatura es el de Cultura y Política Lingüística con 10 Ordenes emitidas por el Consejero de Cultura y Política Lingüística. En segundo lugar, se sitúa el Departamento de Gobernanza Pública y Autogobierno con una Orden emitida por el Consejero de Gobernanza Pública y Autogobierno y 7 Resoluciones adoptadas por

80 Datos extraídos de la Web del Gobierno Vasco.

81 Decreto 149/2017, de 25 de abril, por el que se dispone el cese de la Secretaría General de Emakunde-Instituto Vasco de la Mujer y Decreto 184/2017, de 27 de junio, por el que se nombra Secretaría General de Emakunde-Instituto Vasco de la Mujer.

82 Fuente de elaboración propia a partir de datos extraídos de la Web del Gobierno Vasco. 
el director de la Secretaría del Gobierno y de Relaciones con el Parlamento. Ocupan el tercer puesto el Departamento de Empleo y Políticas Sociales — con 4 Resoluciones adoptadas por el Director de Servicios Sociales - y el de Educación en cuyo caso han sido 2 las Ordenes adoptadas por la Consejera de Educación y 2 las Resoluciones emitidas por la Viceconsejera de Educación. Y el Departamento menos activo es el de Hacienda y Economía con una Orden aprobada el 26 de septiembre de 2018 por el consejero titular.

De un total de 27 disposiciones aprobadas en la legislatura en temas relativos a la igualdad de mujeres y hombres solo 4 tienen al frente del órgano promotor a una mujer, lo que supone solo un 14,8\% del total de la normativa aprobada por el ejecutivo autonómico en la materia. Estos datos demuestran que no existe una directa relación entre impulso de políticas de igualdad y presencia de mujeres en Altos Cargos.

Si fijamos nuestra atención ahora en el ámbito de las iniciativas parlamentarias presentadas en la XI Legislatura el escenario es el siguiente. Respecto a iniciativas parlamentarias desde Lehendakaritza se ha presentado un Proyecto de Ley de segunda modificación de la Ley para la igualdad de Mujeres y Hombres y han sido 5 las Proposiciones de Ley tramitadas ante el Parlamento Vasco. En concreto, 3 presentadas por el Grupo Parlamentario de Elkarrekin Podemos ${ }^{83}$ y 2 por el de EH Bildu ${ }^{84}$.

Por su parte, con relación a las iniciativas de impulso político los datos son los que se reflejan en la siguiente tabla.

TABLA 9. Iniciativas de impulso político presentadas en la XI Legislatura ${ }^{85}$.

\begin{tabular}{|c|c|c|c|}
\hline Grupo parlamentario proponente & $\begin{array}{c}\text { Proposiciones } \\
\text { no de ley }\end{array}$ & $\begin{array}{c}\text { Mociones } \\
\text { consecuencia } \\
\text { de interpelación }\end{array}$ & $\begin{array}{c}\text { Declaraciones } \\
\text { institucionales }\end{array}$ \\
\hline Euskal Herria Bildu & 18 & 3 & \\
\hline Elkarrekin Podemos & 20 & 5 & \\
\hline $\begin{array}{c}\text { EA-Nacionalistas Vascos/EH Bildu/ } \\
\text { Socialistas Vascos }\end{array}$ & 1 & & 5 \\
\hline Pleno & & & \\
\hline
\end{tabular}

83 Son las siguientes Proposiciones de Ley: la de modificación de la Ley 171998, de 5 de febrero, del Tribunal Vasco de Cuentas Públicas/Herri-Kontuen Epaitegia; la de modificación de la Ley 3/2016, de 7 de abril, para la inclusión de determinadas clausulas sociales en la contratación pública; y la referente a medidas y acciones urgentes de impulso y mejora de las políticas para la igualdad de mujeres y hombres y para una sociedad libre de violencias machistas.

84 El Grupo Parlamentario de EH Bildu ha presentado la Proposición de Ley para la inclusión de determinadas clausulas sociales en la contratación pública y la Proposición de Ley de modificación de la Ley $7 / 2015$ de 30 de junio.

${ }_{85}$ Fuente de elaboración propia a partir de datos extraídos de la web del Parlamento Vasco.

(C) UNED. Revista de Derecho Politico

N. ${ }^{\circ} 109$, septiembre-diciembre 2020, págs. 153-189 


\begin{tabular}{|c|c|c|c|}
\hline Grupo parlamentario proponente & $\begin{array}{c}\text { Proposiciones } \\
\text { no de ley }\end{array}$ & $\begin{array}{c}\text { Mociones } \\
\text { consecuencia } \\
\text { de interpelación }\end{array}$ & $\begin{array}{c}\text { Declaraciones } \\
\text { institucionales }\end{array}$ \\
\hline $\begin{array}{c}\text { EA-Nacionalistas Vascos/EH Bildu/ } \\
\text { Elkarrekin Podemos/Socialistas } \\
\text { Vascos/Popular Vasco }\end{array}$ & 39 & 8 & 6 \\
\hline TOTAL & \multicolumn{2}{|c}{} \\
\hline
\end{tabular}

Puede observarse que de un total de 58 iniciativas de impulso político presentadas en la legislatura la gran mayoría han sido propuestas por el Grupo Parlamentario Elkarrekin Podemos y Euskal Herria Bildu. En concreto, el primero 25 y el segundo 21 lo que implica que Elkarrekin Podemos ha presentado un 43,1\% del total de iniciativas y Euskal Herria Bildu el 36,2\%. De modo que curiosamente es el Grupo Parlamentario que tiene menos representación femenina en el Parlamento Vasco (36,3\% frente a un $63,7 \%$ de hombres) el que lidera el ranking en cuanto a número de iniciativas de impulso político presentadas en materia de igualdad y el Grupo con más escaños ocupados por mujeres $(66,6 \%)$ es el que ocupa el segundo lugar. La conclusión parece bastante clara: no tenemos elementos para sostener que una mayor presencia de mujeres en el Parlamento Vasco asegure una actitud más activa en cuanto al impulso de iniciativas que redunden a favor de la igualdad entre mujeres y hombres.

\section{ALGUNAS REFLEXIONES CONCLUSIVAS}

El sistema de cuotas ha permitido paliar, desde un punto de vista cuantitativo, el déficit democrático del que adolece el sistema de la democracia representativa permitiendo el tránsito hacia la democracia paritaria. Un sistema de cuotas que en ningún caso ha de tener virtualidad finalista sino instrumental, puesto que ha de ser el cauce para democratizar la democracia permitiendo una participación igualitaria de mujeres y hombres en los centros de toma de decisión política que posibilite la implementación de medidas capaces de eliminar las desigualdades. El sistema de cuotas ha de facilitar que la democracia se convierta en un verdadero instrumento catalizador capaz de trasformar la sociedad para lo que consideramos necesario la inclusión cualitativa de las mujeres en los centros de decisión política más allá de la mera presencia numérica de estas.

Situados ahora en el concreto ámbito de la Comunidad Autónoma Vasca, se observa que las modificaciones normativas incorporadas en la Ley de Elecciones al Parlamento Vasco y en la Ley del Gobierno para atender al mandato legal previsto en la Ley 4/2005, han servido para paliar las ausencias de mujeres en ciertos espacios del espectro político vasco y aumentar su presencia tanto en el Legislativo como en el 
Ejecutivo autonómicos. A partir de las elecciones del 2005 se produce un aumento destacable de la presencia de mujeres tanto en el caso del Parlamento como en el del Gobierno Vasco y de la ocupación por parte de estas de cargos en uno y otro órgano político. En este sentido, por ejemplo, es en la VIII legislatura, que comienza su andadura en el 2005, cuando por primera vez la presidencia del Parlamento es ostentada por una mujer. Por tanto, sí puede aseverarse la eficacia de la Ley 4/2005 si el parámetro de medición es el aumento de la presencia o participación de mujeres en cargos de responsabilidad política.

Ahora bien, para determinar cómo impacta la presencia de mujeres en la eliminación de la discriminación estructural es necesario observar otros indicadores como son: la evaluación del impacto de género en las políticas públicas autonómicas y las iniciativas parlamentarias y gubernamentales presentadas en la actual legislatura en materia de igualdad. Con carácter general parece poder concluirse que esa presencia de mujeres en los centros de decisión política en el ámbito autonómico vasco es una condición necesaria para la implementación de políticas públicas con perspectiva de género que sean capaces de ejercer una función transformadora de la sociedad, pero no es necesariamente suficiente. Y desde una perspectiva particular, se ha podido constatar que tanto el primer indicador como el segundo presentan serias debilidades y no pocos déficits en aras a establecer una relación de causalidad entre presencia de mujeres y el grado de efectividad para incorporar la perspectiva de género en las políticas públicas y ello por razones de muy diversa índole.

La presencia de mujeres en el legislativo y autonómico vascos no asegura automáticamente la representatividad de los intereses de este colectivo o la consecución de la igualdad cualitativa. Como hemos advertido, la participación política entendida como mera presencia de mujeres en instituciones políticas no resulta suficiente para asegurar que estas puedan hacer valer su voz en los procesos de decisión política como grupo subordinado y ejercer un papel transformador. Así, se advierte la necesidad de seguir trabajando para lograr que la ocupación del espacio de toma de decisiones por las mujeres redunde en la consecución de mayores cuotas de justicia social.

En fin, no puede negarse que la Ley del 2005 ha supuesto un avance por lo que respecta a la mayor participación política de las mujeres en el Parlamento y Gobierno Vasco, pero también es evidente que todavía hay mucho camino por recorrer si queremos que tal presencia ejerza un papel trasformador en la sociedad. Lo que de verdad interesa, es que la participación política de las mujeres permita transformar la sociedad abordando los problemas estructurales de desigualdad existentes mediante el diseño y ejecución de políticas públicas con impacto de género. Y en este sentido, como acabamos de avanzar, el camino por andar es todavía largo. 
Title:

Parity democracy and the impact of gender on public policies: analysis of the case of the Basque Autonomous Community

\title{
Summary:
}

I. INTRODUCTION. II. REPRESENTATIVE DEMOCRACY AS A STARTING POINT. III. FROM REPRESENTATIVE DEMOCRACY TO PARITY DEMOCRACY: THE QUOTA SYSTEM IV. THE GENDER PERSPECTIVE IN REGIONAL POLICIES: THE CASE OF THE BAC 4.1. Presence of women in the Basque Parliament and Government. 4.2. The evaluation of the impact of gender in autonomous public policies. 4.3. Parliamentary and governmental initiatives in the area of equality V. SOME CONCLUDING REFLECTIONS.

\section{Resumen:}

El modelo de democracia representativa previsto en la Constitución de 1978 adolece de un cierto déficit en el sentido que impide a las mujeres lograr la necesaria participación en condiciones de igualdad en los centros de toma de decisión política. A los efectos de corregir la fallida representación de las mujeres, la Ley 4/2005, de 18 de febrero, para la Igualdad de Mujeres y Hombres incorpora la necesidad de respetar la paridad. El trabajo analiza los efectos que tiene el mandato de la paridad en el ámbito autonómico vasco. Se trata de determinar si la mayor presencia de mujeres en el Parlamento y en el Gobierno autonómico se ha reflejado en políticas públicas capaces de transformar esta sociedad en una más igualitaria. Y para precisar si la presencia de mujeres en puestos de decisión política va más allá de una mera participación formal se ha llamado la atención sobre los siguientes 2 indicadores: la evaluación del impacto de género de las políticas públicas autonómicas; y, las iniciativas parlamentarias y gubernamentales impulsadas en materia de igualdad.

\begin{abstract}
:
The model of representative democracy provided by the 1978 Constitution suffers from a certain deficit in the sense that it prevents women from achieving the necessary participation in conditions of equality in political decision-making centres. In order to rectify the under-representation of women, Law 4/2005, of 18 February, for the Equality of Women and Men incorporates the need to respect parity. The work analyses the effects that the parity mandate has on the Basque Autonomous Community. The aim is to determine whether the greater presence of women in Parliament and in the autonomous government has been reflected in public policies capable of transforming this society into a more egalitarian one. In order to determine whether the presence of women in political decision-making positions goes beyond mere formal participation, attention has been
\end{abstract}


drawn to the following two indicators: evaluation of the gender impact of autonomous public policies; and, parliamentary and governmental initiatives promoted in the area of equality.

\section{Palabras clave:}

Participación política; Democracia paritaria; Sistema de cuotas; Impacto de género; políticas públicas.

\section{Keywords:}

Political participation; Parity democracy; Quota system; Gender impact; public policies. 
